\title{
The theory of interceptor-protector action of DNA binding drugs
}

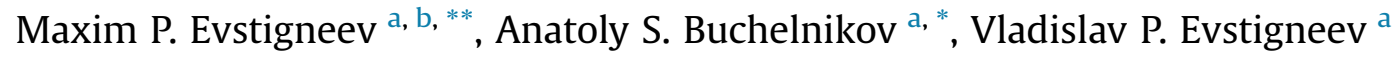 \\ a Sevastopol State University, Sevastopol, Russia \\ ${ }^{\mathrm{b}}$ Belgorod State University, Belgorod, Russia
}

\section{A R T I C L E I N F O}

\section{Article history:}

Received 20 February 2019

Received in revised form

1 April 2019

Accepted 9 April 2019

Available online 13 April 2019

\section{Keywords:}

Interceptor action

Protector action

DNA binding drugs

Hetero-association

Competitive binding

\begin{abstract}
A B S T R A C T
The review discusses the theory of interceptor-protector action (the IPA theory) as the new selfconsistent biophysical theory establishing a quantitative interrelation between parameters measured in independent physico-chemical experiment and in vitro biological experiment for the class of DNA binding drugs. The elements of the theory provide complete algorithm of analysis, which may potentially be applied to any system of DNA targeting aromatic drugs. Such analytical schemes, apart from extension of current scientific knowledge, are important in the context of rational drug design for managing drug's response by changing the physico-chemical parameters of molecular complexation.
\end{abstract}

() 2019 Elsevier Ltd. All rights reserved.

\section{Contents}

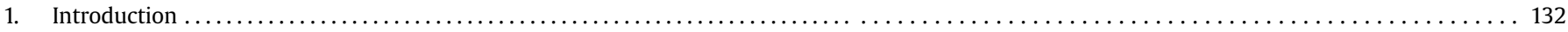

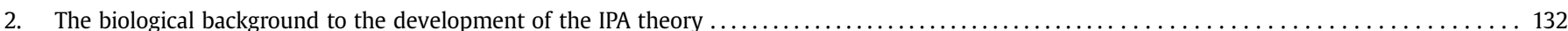

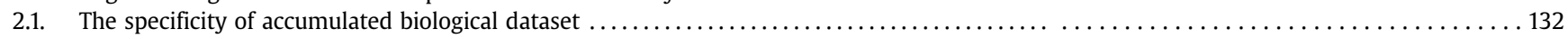

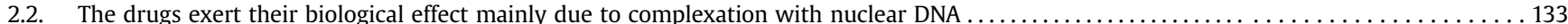

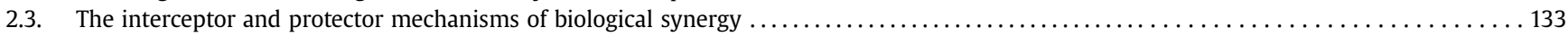

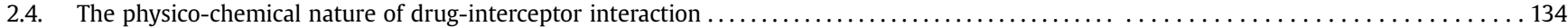

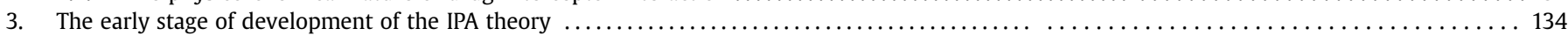

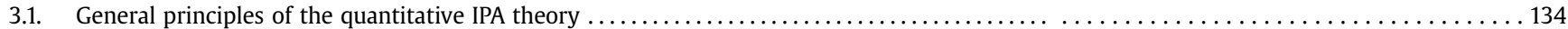

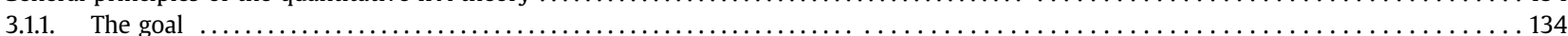

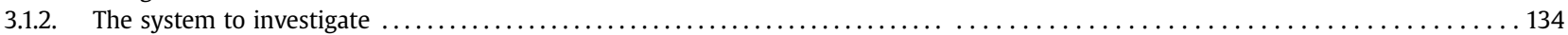

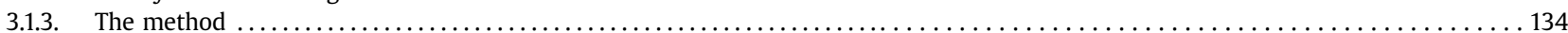

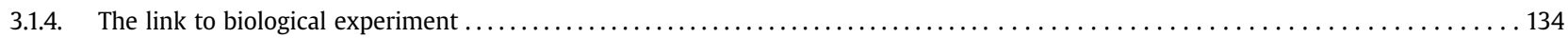

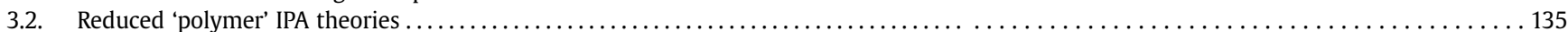

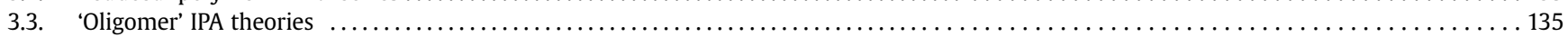

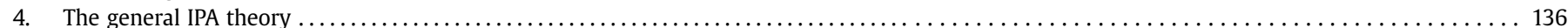

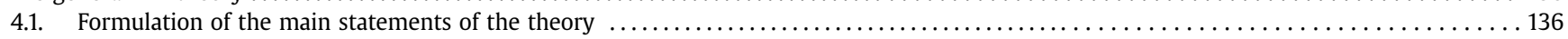

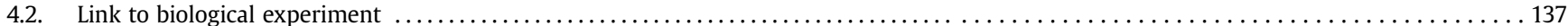

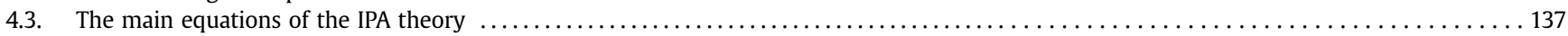

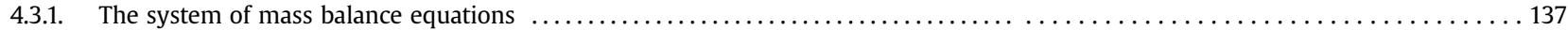

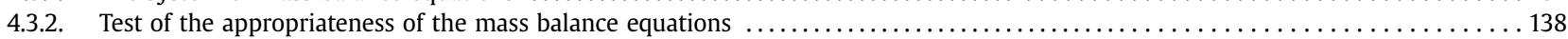

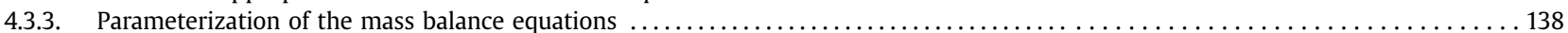

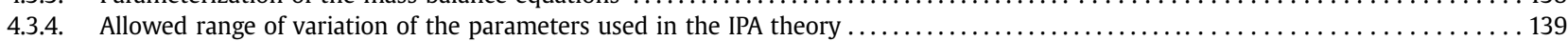

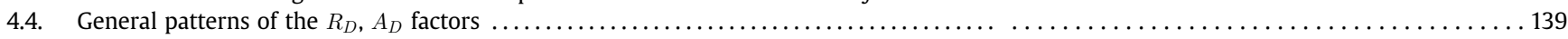

\footnotetext{
* Corresponding author.

** Corresponding author. Sevastopol State University, Sevastopol, Russia.

E-mail addresses: max_evstigneev@mail.ru (M.P. Evstigneev), tolybas@rambler. ru (A.S. Buchelnikov).
} 


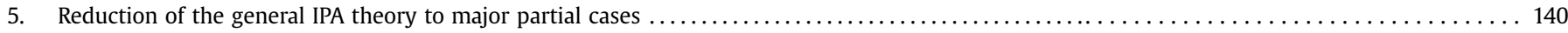

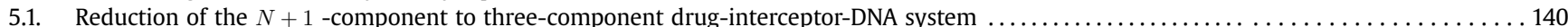

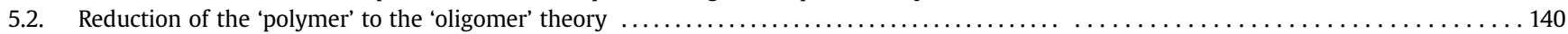

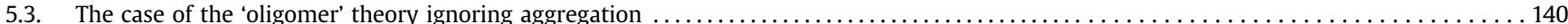

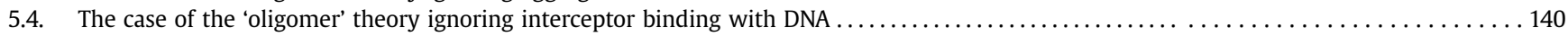

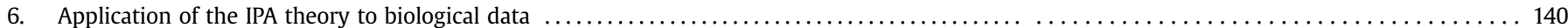

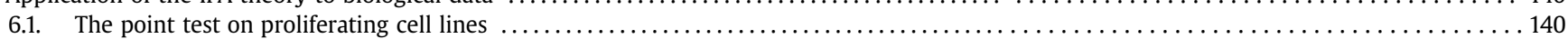

6.2. Evaluation of biological data from concentration dependence of induced biological effect in vitro ....................... 141

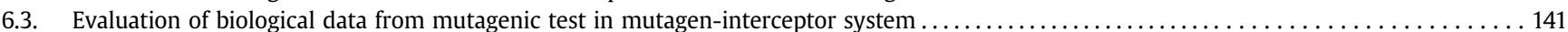

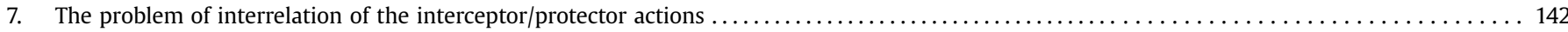

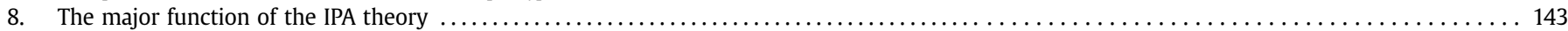

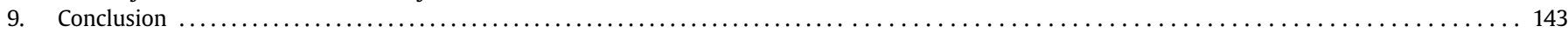

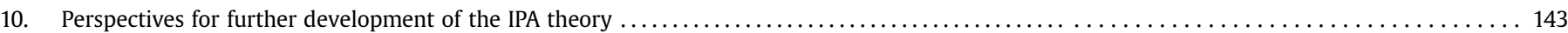

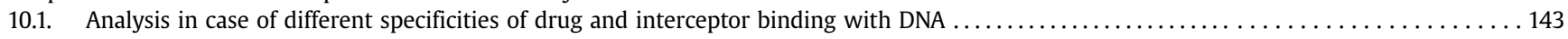

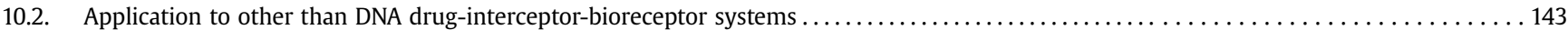

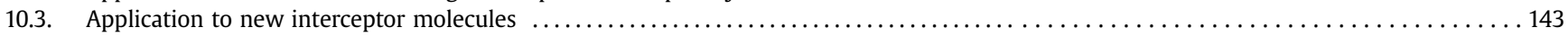

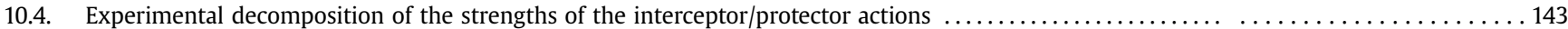

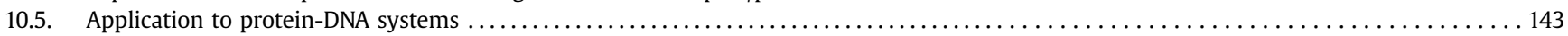

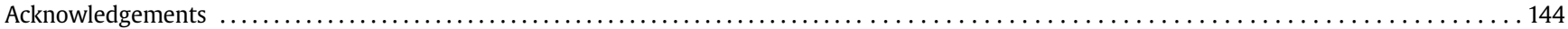

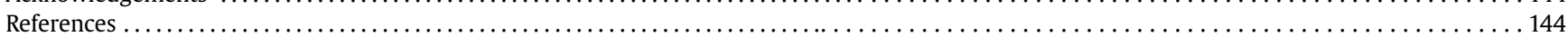

\section{Introduction}

Biological synergy developed during administration of combinations of biologically active compounds (BACs) is the key property extensively used by a number of modern protocols of cancer chemotherapy. Thus, the ability to manage and predict the response of biosystem to action of BACs' combinations is of paramount importance for stimulating further progress in this field of medicine.

One of the most well studied BACs, which exert biological synergy on simultaneous administration, are aromatic DNA targeting drugs (Schwab et al., 2000; Evstigneev, 2010, 2013; Woziwodzka et al., 2013a). The typical examples are the combinations of aromatic antibiotics Doxorubicin-Actinomycin D (Ridge et al., 1994), Doxorubicin-Amsacrine (Bernier et al., 1989), Camptothecin-Chloroquine (Sorensen et al., 1997) etc. It is considered that for the range of aromatic drugs the possible mechanism of synergy could be associated with two molecular processes occurring in biological fluid (inside and/or outside cell), viz. competition for DNA binding sites and non-covalent complexation of drugs with each other (also referred to as heteroassociation or hetero-complexation). If the molecular complexation lies behind the experimentally observed biological synergy of aromatic drugs, it follows that some quantitative correlation of biological parameters and physico-chemical parameters of intermolecular interaction should be the case. Implicitly or explicitly, the search of such correlation has been carried out by many researchers during the past 50 years, which has enabled to establish some important patterns of the biological synergy of aromatic drugs and formulate the basics of the so-called theory of interceptor-protector action (the IPA theory). In total, the biological and physico-chemical data concerning the interaction of DNA binding drugs, accumulated to date, as well as the level of understanding the mechanism of biological synergy, are considered to be sufficient for building the general IPA theory.

\section{The biological background to the development of the IPA theory}

The biological data accumulated to date with respect to the systems containing the mixtures of aromatic drug molecules has been extensively reviewed with the most recent contribution given in refs (Woziwodzka et al., 2013a; Evstigneev, 2013) (see also references therein). Here we shall provide some general conclusions that can be drawn regarding the biological specificity of the combinations of aromatic BACs:

\subsection{The specificity of accumulated biological dataset}

The biological data generated to date was mainly obtained on in vitro level (various human cell lines (e.g. refs (Traganos et al., 1993; Hill et al., 2011; Skamrova et al., 2014; Panchuk et al., 2015; Prylutska et al., 2017a; Prylutska et al., 2017b)), bacteria mutagenic tests (e.g. refs (Woziwodzka et al., 2011; Woziwodzka et al., 2013b))) with very few instances when the apparent biological synergy was observed in vivo (e.g. refs (Sadzuka et al., 1995; Kakuyamanee Iwazaki and Sadzuka, 2001; Prylutska et al., 2014; Prylutska et al., 2015)). The drugs which are used in experiment together, most often are categorized for two types: the main drug which exerts biological effect (say, antibiotic), and the second drug, which does not have any apparent biological interaction with the main drug, and is called 'interceptor' molecule (in practice, the conditions of experiment are chosen in a way to minimize the biological effect of the interceptor drug). The typical biological experiment is carried out as the measurement of change of biological effect of the main drug on addition of interceptor molecule, relative to the action of the drug alone. The corresponding results are given in qualitative or quantitative form (e.g. the measurement of $\mathrm{IC}_{50}$ factor as the biological parameter). The main properties of the measured biological parameter are (Evstigneev, 2013; Traganos et al., 1991a, 1991b, 1993; Hill et al., 2011; Skamrova et al., 2014; Panchuk et al., 2015; Kapuscinski et al., 2002; Ganapathi et al., 1986; Lyles and Cameron, 2002; Bedner et al., 2001; Borowik et al., 2018):

- the most significant and reproducible changes are observed in cases when drug-interceptor combinations were administered and/or present in the vicinity of target cells together. Sequential administration commonly leads to attenuation or disappearance of biological synergy;

- strong dependence on concentration of interceptor (doseactivity relationship); 
- full or partial reversibility of the dose-activity relationship;

- existence of quantitative correlation between the measured biological parameter and the parameters of molecular complexation (the equilibrium constant of drug-interceptor hetero-association). To the best of our knowledge this property was first noted in ref (Dashwood and Guo, 1993). with respect to drug-chlorophyllin systems and further confirmed for other interceptors (Skamrova et al., 2014; Evstigneev et al., 2005, 2006a, 2006b, 2008, 2011a; Hernandez Santiago et al., 2009; Buchelnikov et al., 2012; Buchelnikov and Evstigneev, 2014).

\subsection{The drugs exert their biological effect mainly due to complexation with nuclear DNA}

Many of known BACs which exert biological synergy in combination, belong to the group of aromatic DNA intercalators which directly or indirectly induce biological effect due to covalent or non-covalent binding with DNA. The most typical examples of such drugs are antitumor antibiotics (doxorubicin, topotecan, mitoxantrone) and mutagens (acridine orange, ethidium bromide, imidazole-quinoline amines).

\subsection{The interceptor and protector mechanisms of biological synergy}

It was established that the mechanisms of mutual influence of aromatic heterocyclic compounds on the medico-biological activity of each other may feature either covalent, or non-covalent type of action, exerted in specific and non-specific forms. However, the fundamental similarity of the mechanisms was noted, originating from the physical interaction of aromatic molecules in mixed solution either at the nucleic acid level or at the level of direct interaction between the solute molecules. These mechanisms were formulated in the form of two molecular processes (Fig. 1):
- protector (Skamrova et al., 2014; Traganos et al., 1991a, 1991b; Evstigneev et al., 2005, 2006a, 2006b, 2008, 2011a; Hernandez Santiago et al., 2009; Buchelnikov et al., 2012; Buchelnikov and Evstigneev, 2014; Davies et al., 2001; Chin et al., 2012; Maria Johnson et al., 2003a), i.e. competition of the drug and interceptor for DNA binding sites leading to removal of the drug from DNA as a result of interceptor-DNA binding, and

- interceptor (Traganos et al., 1991a, 1991b, 1993; Hill et al., 2011; Skamrova et al., 2014; Panchuk et al., 2015; Woziwodzka et al., 2011, 2013b; Kapuscinski et al., 2002; Ganapathi et al., 1986; Lyles and Cameron, 2002; Bedner et al., 2001; Borowik et al., 2018; Dashwood and Guo, 1992, 1993; Evstigneev et al., 2005, 2006a, 2006b, 2008, 2011a; Hernandez Santiago et al., 2009; Buchelnikov et al., 2012; Buchelnikov and Evstigneev, 2014; Davies et al., 2001; Chin et al., 2012; Maria Johnson et al., 2003a; Piosik et al., 2002, 2003, 2005, 2010; Ulanowska et al., 2005, 2007; Tachino et al., 1994; Pietrzak et al., 2006, 2008; Gołuński et al., 2013, 2015; Banerjee et al., 2011; Kharasch and Novak, 1981; Raiczyk and Pinto, 1988; Ramu et al., 2000; Arimoto et al., 1993; Ardelt et al., 2001; Ridge et al., 1994), i.e. hetero-association between the Drug and Interceptor leading to formation of inactive hetero-complexes unable to bind with DNA (an analogue of host-guest interaction).

The interceptor mechanism has long been known and the molecules acting by this mechanism were termed as 'interceptor molecules' or 'scavengers' (Woziwodzka et al., 2013a; Evstigneev, 2013; Dashwood and Guo, 1992; Gołuński et al., 2016; Odin, 1997). However, the existence of two molecular mechanisms, operating simultaneously in drug-interceptor-DNA systems, suggests that the term 'interceptor molecule' should therefore be understood more broadly.

The most typical aromatic interceptor molecules, for which the interceptor-protector hypothesis is commonly discussed as being

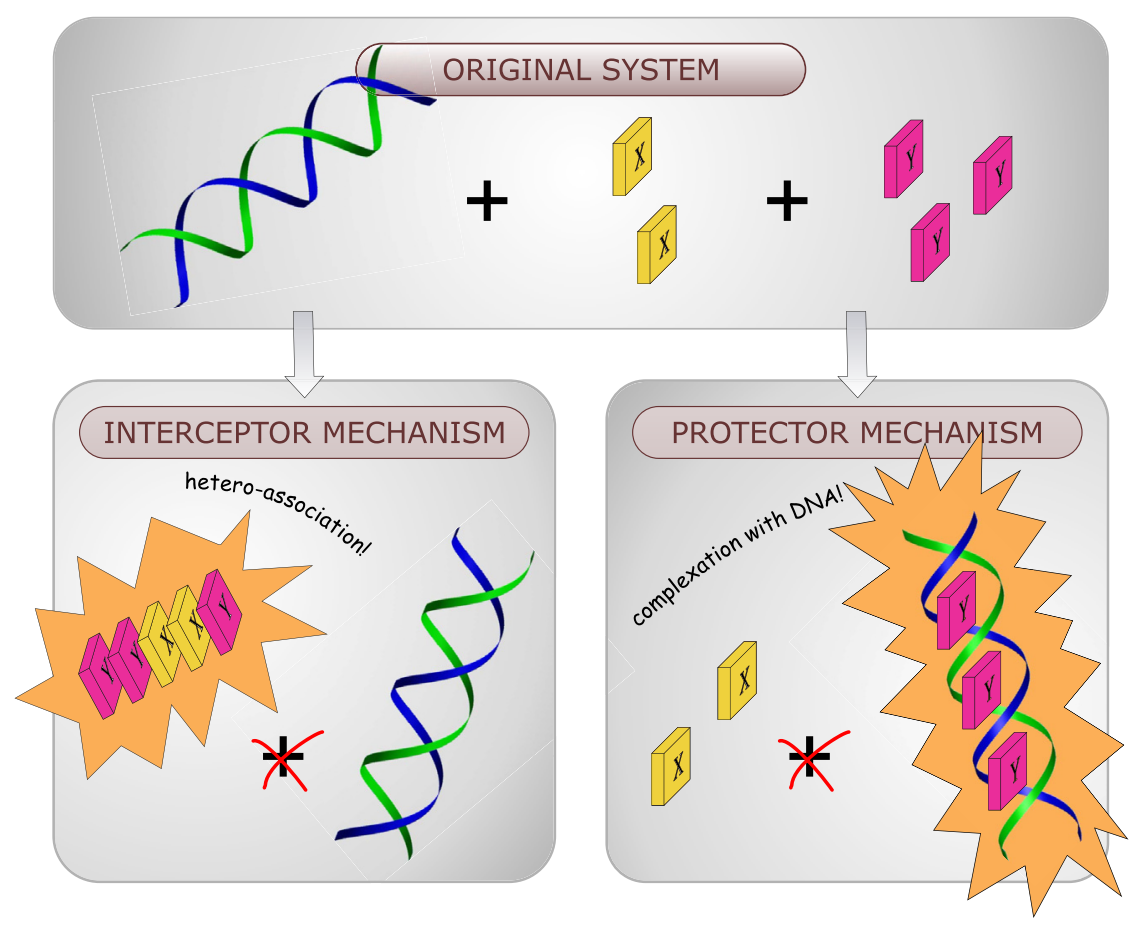

Fig. 1. Schematic representation of the interceptor and protector mechanisms. 
superior to other mechanisms, belong to four groups (Fig. 2):

- methylxanthines (caffeine, theophylline, pentoxifylline) (Woziwodzka et al., 2011, 2013a, 2013b; Evstigneev, 2013; Traganos et al., 1991a, 1991b, 1993; Hill et al., 2011; Skamrova et al., 2014; Sadzuka et al., 1995; Kakuyamanee Iwazaki and Sadzuka, 2001; Kapuscinski et al., 2002; Ganapathi et al., 1986; Lyles and Cameron, 2002; Bedner et al., 2001; Evstigneev et al., 2006a, 2006b, 2008, 2011a; Hernandez Santiago et al., 2009; Buchelnikov et al., 2012; Buchelnikov and Evstigneev, 2014; Davies et al., 2001; Chin et al., 2012; Maria Johnson et al., 2003a; Piosik et al., 2002, 2003, 2005, 2010; Ulanowska et al., 2005, 2007; Gołuński et al., 2013, 2015, 2016; Banerjee et al., 2011);

- polyphenols (vitamin $\mathrm{B}_{2}$ ) (Woziwodzka et al., 2013a; Evstigneev, 2013; Evstigneev et al., 2005, 2008; Kharasch and Novak, 1981; Raiczyk and Pinto, 1988; Ramu et al., 2000; Odin, 1997);

- porphyrins (of which chlorophyllin is most well studied) (Woziwodzka et al., 2013a; Evstigneev, 2013; Dashwood and Guo, 1992, 1993; Buchelnikov and Evstigneev, 2014; Tachino et al., 1994; Pietrzak et al., 2006, 2008; Arimoto et al., 1993; Ardelt et al., 2001);

- fullerene $C_{60}$ (the most recent discovered interceptor molecule) (Skamrova et al., 2014; Panchuk et al., 2015; Prylutska et al., 2014, 2015, 2017a, 2017b; Borowik et al., 2018; Bilobrov et al., 2019).

\subsection{The physico-chemical nature of drug-interceptor interaction}

It was noted that aromatic BACs contain conjugated aromatic<smiles>Cn1c(=O)c2c(ncn2C)n(C)c1=O</smiles>

Caffeine
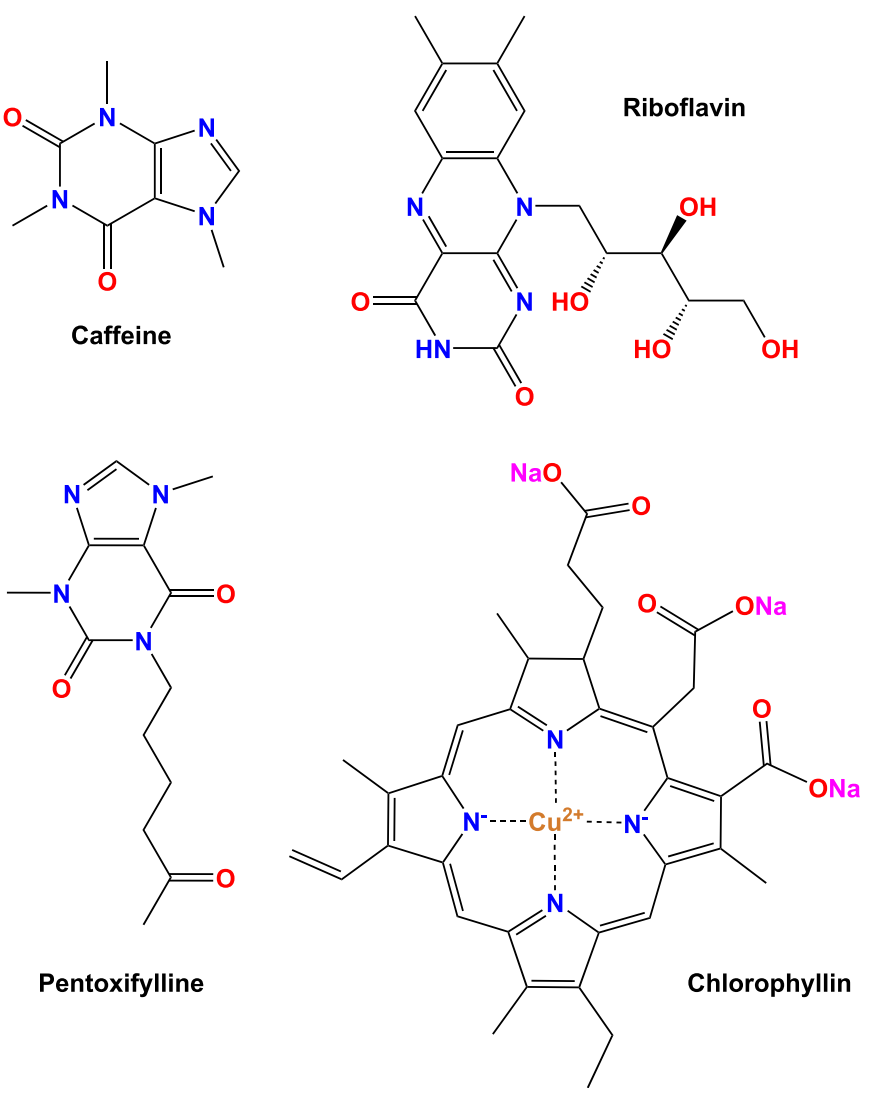

Fig. 2. Structures of the typical interceptor molecules. heterocycles which make them essentially rigid and flat objects. Such molecules feature strong $\pi$-stacking interactions with each other which is considered to be the principal driving force stabilizing intercalated complexes of aromatic drugs with DNA (Evstigneev, 2010; Kostjukov et al., 2009; Evstigneev and Shestopalova, 2014), as well as drug-interceptor hetero-complexes (Borowik et al., 2018; Larsen et al., 1996; Kostjukov et al., 2011; Evstigneev, 2014). This property allows one to predict the biological interaction for other drugs' combinations. In fact, the prediction of interceptor action of pentoxifylline (Woziwodzka et al., 2011, 2013b) and fullerene (Skamrova et al., 2014; Panchuk et al., 2015) has been made based on the knowledge of the physico-chemical nature of stabilizing property of $\pi$-stacking.

The above-mentioned specificities of drug-interceptor-DNA systems were considered as starting point for creating the IPA theory.

\section{The early stage of development of the IPA theory}

\subsection{General principles of the quantitative IPA theory}

\subsubsection{The goal}

As discussed above, the biological data accumulated to date with respect to biological synergy observed on simultaneous administration of a combination of aromatic BACs (i.e. drug-interceptor pairs) contain a correlation of the measured biological parameter with physico-chemical parameters of molecular complexation. Hence, the aim of the IPA theory should be the prediction of relative change in biological effect induced by addition of interceptor molecule to biological system containing aromatic drug.

\subsubsection{The system to investigate}

The fundamental mechanisms of biological synergy, viz. protector and interceptor, in general case may operate simultaneously and act on the level of drug-interceptor interaction (the interceptor mechanism) or drug-DNA/interceptor-DNA interaction (the protector mechanism). It follows that the minimal model of synergistic interaction should be the three-component drug-interceptor-DNA system.

\subsubsection{The method}

In the majority of papers related to the IPA theory (i.e. those which discuss the three- or more-component systems of different interacting molecules including biopolymer), the search of the link between biological and physico-chemical parameters used solely equilibrium thermodynamics approach. It follows that the quantitative IPA theory should use at least two fundamental laws of equilibrium thermodynamics, viz. the mass balance law and the law of mass action, written with respect to drug-interceptor-DNA system.

\subsubsection{The link to biological experiment}

As long as the interceptor/protector mechanisms are fully physico-chemical processes, their effect should be expressed in terms of physico-chemical parameters of molecular complexation, i.e. equilibrium complexation constants and equilibrium concentrations. The utilization of relative change of biological parameter as a measure of biological effect induced by addition of interceptor (see section 2) suggests that the key quantities which could be obtained from the solution of equations of mass balance law, are mole fractions of different types of drug-DNA complexes. The latter could then be associated with the measured biological parameter.

The principles outlined above explain the evolution of the IPA theory from the early stage dated back to 2000 up to now, which will be detailed below. 


\subsection{Reduced 'polymer' IPA theories}

The reduced IPA theories are characterized by consideration of single molecular process, interceptor or protector, or any other reduction of the dynamic equilibrium in solution, and the use of polymeric DNA as a model of bioreceptor.

The neglecting of the interceptor mechanism results in classical competitive binding scheme well known in enzyme (e.g. ref (Wang et al., 1998; Peacock and Jaynes, 2017)) as well as nucleic acid chemistry (e.g. refs (Zasedatelev et al., 1971; McGhee and von Hippel, 1974; Nechipurenko et al., 1984; Baranovskii et al., 2011)), which uses classical Scatchard or McGhee - von Hippel approaches for describing molecular equilibrium in three-component systems. The mole fractions $(\theta)$ of $\boldsymbol{X}$-DNA and $\boldsymbol{Y}$-DNA complexes (3.1a) and the mass balance law (3.1b) in $\boldsymbol{X}$-Y -DNA system are written as

$$
\begin{aligned}
& C_{T C}=C_{C}\left(\frac{1+K_{A C}\left(C_{A}+\frac{1}{2} K_{A A} C_{A}^{2}\right)}{1-C_{C}\left(K_{C C}+K_{A C}^{2}\left(C_{A}+\frac{1}{2} K_{A A} C_{A}^{2}\right)\right)}\right)^{2} ; \\
& C_{A C}=K_{A C} \frac{2 C_{C}\left(C_{A}+\frac{1}{2} K_{A A} C_{A}^{2}\right)\left(1-C_{C}\left(K_{C C}-K_{A C}\right)\right)}{\left(1-C_{C}\left(K_{C C}+K_{A C}^{2}\left(C_{A}+\frac{1}{2} K_{A A} C_{A}^{2}\right)\right)\right)^{2}} ; \\
& C_{A A}=\frac{C_{A}^{2}}{2}\left(\frac{1-C_{C}\left(K_{C C}-K_{A C}\right)}{1-C_{C}\left(K_{C C}+K_{A C}^{2}\left(C_{A}+\frac{1}{2} K_{A A} C_{A}^{2}\right)\right)}\right)^{2} ;
\end{aligned}
$$

$$
\left\{\begin{array}{ll}
x_{0} & =x_{1}+\theta_{X} N_{0} \\
y_{0} & =y_{1}+\theta_{Y} N_{0}
\end{array},\right.
$$

where $x_{1}, y_{1}$ and $x_{0}, y_{0}$ are the concentrations of monomers and total concentrations of drugs $\boldsymbol{X}$ and $\boldsymbol{Y}$, respectively; $N_{0}$ is total DNA concentration in base pairs per mole; $n_{X}, n_{Y}$ and $K_{X N}, K_{Y N}$ are the number of base pairs per one bound ligand (the binding site size) and equilibrium DNA complexation constant, respectively. The pure competitive binding scheme (3.1) should be considered here as a potentially important partial case of the IPA theory.

Another partial case presented in most general case in ref (Gołuński et al., 2015). was related to the most widely spread case when the protector mechanism could be ignored and the heteroassociation between drug and interceptor completely governs the biological synergy. This case was successfully applied to drugchlorophyllin-DNA (Pietrzak et al., 2006, 2008) and drugmethylxanthine-DNA (Piosik et al., 2010; Gołuński et al., 2015, 2016) systems. The basic equations to treat dynamic equilibrium were obtained by merging the hetero-association model (Kapuscinski and Kimmel, 1993) and McGhee - von Hippel model (McGhee and von Hippel, 1974) (the author designations preserved):

$$
\frac{r}{C_{A}}=K_{I}(1-n r)\left(\frac{1-n r}{1-(n-1) r}\right)^{n-1}
$$

$$
C_{T A}=C_{A}\left(1+K_{A A} C_{A}\right)\left(\frac{1-C_{C}\left(K_{C C}-K_{A C}\right)}{1-C_{C}\left(K_{C C}+K_{A C}^{2}\left(C_{A}+\frac{1}{2} K_{A A} C_{A}^{2}\right)\right)}\right)^{2}
$$

$$
C_{C C}=K_{C C}\left(\frac{C_{C}\left(1+K_{A C}\left(C_{A}+\frac{1}{2} K_{A A} C_{A}^{2}\right)\right)}{1-C_{C}\left(K_{C C}+K_{A C}^{2}\left(C_{A}+\frac{1}{2} K_{A A} C_{A}^{2}\right)\right)}\right)^{2}
$$

where $C, K, r, n$ are concentrations, equilibrium binding constants, binding density (equivalent to $\theta$ in eq. (3.1)) and site size, respectively; $K_{I}$ is the drug-DNA binding constant; the subscripts ' $A$ ' and ' $C$ ' stand for the drug $(A)$ and interceptor $(C)$; the subscript ' $T$ ' stands for the total concentration. The quantities $C_{A C}, C_{A A}, C_{C C}$ describe the concentration of 'neighborhoods' of certain molecules in all types of complexes in solution; $C_{A}$ and $C_{C}$ are the monomer concentrations. eqs. (3.2b), (3.2c) represent the mass balance law for the drug and interceptor. Apart from neglecting the protector mechanism, eq. (3.2) consider partial case of low drug concentration when its selfassociation may be limited by dimerization.

The first account for both protector and interceptor mechanisms was accomplished in ref (Baranovsky et al., 2009) and later on in ref (Gołuński et al., 2013). by merging eq. (3.1) with simple 1:1 heteroassociation of drug and interceptor molecules. In this case eq. (3.1 b) should be replaced with

$\left\{\begin{array}{l}x_{0}=x_{1}+\theta_{X} N_{0}+K_{h} x_{1} y_{1} \\ y_{0}=y_{1}+\theta_{Y} N_{0}+K_{h} x_{1} y_{1}\end{array}\right.$,

where $K_{h}$ is the hetero-association constant.

This scheme was successfully used to describe spectrophotometric data in drug-methylxanthine-DNA systems (Gołuński et al., 2013, 2016; Baranovsky et al., 2009).

\section{3. 'Oligomer' IPA theories}

The 'oligomer' IPA theories are characterized by account for the protector and interceptor mechanism from one side, and attempts to remove limitation to $1: 1$ hetero-association and dimeric drug self-association, from the other.

In order to describe drug/interceptor-DNA binding the simplest 
one-site non-cooperative Scatchard approach was used in which the binding site size was taken equal to $n=4$ (this value in first approximation well matches the typical $n$ for DNA intercalators), merged with the indefinite hetero-association model (Davies et al., 2000). The first application of this approach dates back to 2000 (Veselkov et al., 2000) and was used until 2002 (Davies et al., 2001, 2002; Veselkov et al., 2002) when it was replaced by more general scheme to be described below.

The principal disadvantage of all models outlined above is the absence of any link to biological experiment. The papers cited just used the solution of mass balance equations to demonstrate the importance of interceptor/protector mechanisms or to correlate the monomer drug concentration with the observed biological effect (e.g. ref (Gołuński et al., 2013)). The first quantitative link to biological data measured in drug-interceptor-DNA systems was suggested in 2005 (Evstigneev et al., 2005) and successfully used until now in many followed up works (Evstigneev, 2010; Skamrova et al., 2014; Evstigneev et al., 2005, 2006a, 2006b, 2008, 2011a; Hernandez Santiago et al., 2009; Buchelnikov et al., 2012, 2013a; Buchelnikov and Evstigneev, 2014). The essence of this approach is to evaluate the effect of addition of interceptor $(\boldsymbol{Y})$ to the system containing the drug $(\boldsymbol{X})$ and DNA $(\boldsymbol{N})$ by means of two factors, $R_{D}$ and $A_{D}$, calculated under conditions of 'switched off interceptor and/or protector mechanisms:

$R_{D}=\frac{f_{C(0)}^{X}-f_{C(c)}^{X}}{f_{C(0)}^{X}-f_{C(h)}^{X}}, \quad A_{D}=\frac{f_{C(0)}^{X}-f_{C}^{X}}{f_{C(0)}^{X}}$

where $f_{C(0)}^{X}$ is the mole fraction of $\boldsymbol{X}$-DNA complexes with 'switched off hetero-association and $\boldsymbol{Y}$-DNA complexation $\left(K_{h}=0, K_{Y N}=0\right)$; $f_{C(c)}^{X}$ is the mole fraction of $\boldsymbol{X}$-DNA complexes under condition of 'switched off $\boldsymbol{X}-\boldsymbol{Y}$ hetero-association and 'switched on' complexation of $\boldsymbol{Y}$ with DNA $\left(K_{h}=0, K_{Y N} \neq 0\right) ; f_{C(h)}^{X}$ is the mole fraction of $\boldsymbol{X}$ DNA complexes under condition of 'switched on' $\boldsymbol{X}$ - $\boldsymbol{Y}$ heteroassociation and 'switched off complexation of $\boldsymbol{Y}$ with DNA $\left(K_{h} \neq 0, K_{Y N}=0\right) ; f_{C}^{X}$ is the relative amount of $\operatorname{drug} \boldsymbol{X}$ bound to DNA in the presence of $\boldsymbol{Y}$, when both mechanisms are operating.

The range of $R_{D}>1$ corresponds to the predominance of $\boldsymbol{Y}$-DNA complexation over $\boldsymbol{X}-\boldsymbol{Y}$ hetero-association (i.e. the 'protector action' of ligand $\boldsymbol{Y}$ ) and $R_{D}<1$ corresponds to hetero-association being the major contribution to the displacement of drug molecules from DNA (i.e. the 'interceptor action' of ligand $\boldsymbol{Y}$ ). As long as the drug $\boldsymbol{X}$ exerts its biological action mainly via complexation with DNA, and so, the quantity $A_{D}$ may be used as a measure of relative change of biological effect of the drug $\boldsymbol{X}$ in the three-component system, $\boldsymbol{X}$-Y DNA, on addition of interceptor molecule $\boldsymbol{Y}$ (the most typical case of experimentally measured relative biological effect directly linked to the $A_{D}$ factor is the standard $\mathrm{IC}_{50}$ or $\mathrm{LC}_{50}$ parameters, or other cell quantities, measured in vitro; see sections 4.2 and 6).

The computation of the mole fractions in eq. (3.4) is accomplished within the framework of the 'oligomer' model, constructed by merging the indefinite hetero-association (Davies et al., 2000) and the Scatchard models, as already noted above, as where $N_{1}$ is the concentration of tetrameric DNA binding sites; $K_{X}$, $K_{Y}$ are the self-association constants. Solution of eq. (3.5) with respect to $x_{1}, y_{1}, N_{1}$ allows one to compute each mole fraction given in eq. (3.4) as $f_{C}^{X}=\frac{K_{X N} X_{1} N_{1}}{x_{0}}$.

The 'oligomer' model based on eqs. (3.4), (3.5) was successfully applied to a wide range of drug-interceptor-DNA systems and enabled to provide the first estimate of experimentally measured and theoretically calculated relative change of biological effect (the $A_{D}$ factor), as well as to evaluate the relative contribution of the interceptor and protector mechanisms (the $R_{D}$ factor). However, the disadvantage of the described approach was a certain lack of generality:

(i) Utilization of the most simple Scatchard model of drug/ interceptor-DNA complexation. The use of McGhee - von Hippel model would be preferable;

(ii) Utilization of approximate indefinite hetero-association model (Davies et al., 2000) accounting for limited types of hetero-complexes (see ref (Evstigneev et al., 2011b) for more discussion);

(iii) utilization of the simplest case of 2-component druginterceptor equilibrium in the presence of DNA. Consideration of general $\mathrm{N}$-component mixture of various drugs with various interceptor molecules would be preferable.

\section{The general IPA theory}

The elements of the theory, removing the drawbacks of the early IPA theories described above, were published in series of works (Skamrova et al., 2014; Evstigneev et al., 2008, 2011a; Buchelnikov et al., 2012, 2013a; Buchelnikov and Evstigneev, 2014). Below these results will be compiled into the general IPA theory.

\subsection{Formulation of the main statements of the theory}

Let us consider the $(N+1)$-component system containing polymeric DNA, the main drug $\boldsymbol{X}$ exerting biological effect which is measured in in vitro experiment, and $(N-1)$ different interceptor molecules, able to non-covalently complex with DNA and with each other. The interceptor molecules will be designated as $\boldsymbol{Y}_{1}, \mathbf{Y}_{2}, \ldots, \mathbf{Y}_{\mathrm{N}}$ 1 and the DNA as $\boldsymbol{P}$. Let us formulate five principal assumptions of the IPA theory:

(i) Biological effect which is measured in in vitro experiment is mainly determined by complexation with nuclear DNA, and the interceptor molecules $\boldsymbol{Y}_{1}, \boldsymbol{Y}_{2}, \ldots, \mathbf{Y}_{\mathrm{N}-1}$ do not biologically interfere with the effect of drug $\boldsymbol{X}$. At least for the range of intercalating drugs and interceptors discussed in section 2 this assumption is valid;

(ii) Biological effect of $\operatorname{drug} \boldsymbol{X}$, under first approximation, may be considered proportional to the mole fraction of $\boldsymbol{X}$-DNA complexes, $f_{C}^{X}$. Indirectly, this assumption is confirmed by proportionality of the observed in vitro biological effect with the concentration, $x_{1}$, of free drug $\boldsymbol{X}$ not bound with interceptors or DNA (e.g. ref (Woziwodzka et al., 2013b));

(iii) biological synergy of drugs' combination $\boldsymbol{X}-\boldsymbol{Y}_{1}-\boldsymbol{Y}_{2}-\ldots-\boldsymbol{Y}_{\mathrm{N}-1}$ is

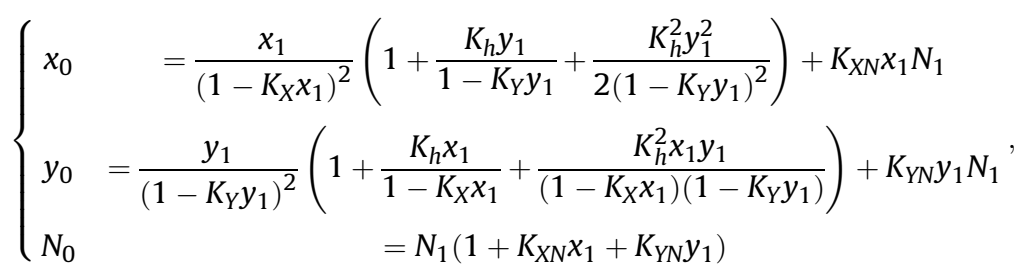


exerted on simultaneous administration into biological system, or by any other route when the drugs $\boldsymbol{X}, \boldsymbol{Y}_{1}, \boldsymbol{Y}_{2}, \ldots, \boldsymbol{Y}_{\mathrm{N}-1}$ appear together in the vicinity of DNA. As discussed in section 2 this assumption is supported by the fact that the most pronounced change in biological effect is achieved on simultaneous administration of druginterceptor combinations;

(iv) The processes of hetero-association $\boldsymbol{X}-\boldsymbol{Y}_{1}, \boldsymbol{X}-\boldsymbol{Y}_{2}, \ldots, \boldsymbol{X}-\boldsymbol{Y}_{\mathrm{N}-1}$ and $\boldsymbol{X}$-DNA, $\boldsymbol{Y}_{1}$-DNA, $\boldsymbol{Y}_{2}$-DNA, ..., $\boldsymbol{Y}_{\mathrm{N}-1}$-DNA complexation are noncovalent and the system may be considered at local thermodynamic equilibrium. This assumption is partly supported by reversibility of the observed experimental changes in vitro (see section 2).

(v) equilibrium constants of hetero-association and DNA complexation, measured in separate physico-chemical experiments under solution conditions close to physiological, may be considered transferrable to the in vitro conditions.

The validity of the set of these assumptions is proved by the ability of the IPA theory to quantitatively predict the relative change in biological effect for given drug-interceptor combinations. There are two immediate consequences from the set of formulated statements:

(i) Any experimentally observed biological synergy of the $\operatorname{drug} \boldsymbol{X}$ and the interceptors $\boldsymbol{Y}$ in vitro is solely due to the effects of molecular complexation: $\boldsymbol{X} / \mathbf{Y}$-DNA complexation and $\boldsymbol{X}$ - $\boldsymbol{Y}$ heteroassociation. Hence, at least two molecular processes govern the biological synergy (Fig. 1), viz. the interceptor (hetero-association between the drug and interceptors leading to formation of inactive hetero-complexes unable to bind with DNA) and protector (competition of the drug and interceptors for DNA binding sites leading to removal of the drug from DNA as a result of interceptorDNA binding);

(ii) Correlation of the observed in vitro biological effect with the physico-chemical parameters of molecular complexation (i.e. equilibrium complexation constants) should be the case. As discussed in section 2 this statement is supported by experimental observations.

\subsection{Link to biological experiment}

The general IPA theory uses the factors $R_{D}$ and $A_{D}$ developed in 'oligomer' theories (see section 3.3) in order to quantify biological data measured in $(N+1)$-component drug-interceptors-DNA system. Their formulation in such system is generally similar to that presented in eq. (3.4), however, it will be given here in terms of binding densities, $\theta_{i}$, of the $i$-th ligand $(i \in 1 \ldots N)$ with DNA (the fraction of DNA bound $i$ th ligand relative to DNA concentration $P_{0}$ ). If the main $\operatorname{drug} \boldsymbol{X}$ exerting biological effect has index $i=1$, the factors can be written as

$R_{D}=\frac{\theta_{1}^{(0)}-\theta_{1}^{(c)}}{\theta_{1}^{(0)}-\theta_{1}^{(h)}}, \quad A_{D}=\frac{\theta_{1}^{(0)}-\theta_{1}}{\theta_{1}^{(0)}}$,

where $\theta_{1}^{(0)}$ is calculated under condition of 'switched off' heteroassociation and Y-DNA complexation (the hetero-association constants and interceptors-DNA binding constants equal to zero); $\theta_{1}^{(c)}$ is calculated under condition of 'switched off $\boldsymbol{X}$ - $\boldsymbol{Y}$ hetero-association and 'switched on' complexation of $\boldsymbol{Y}$ with DNA (only the heteroassociation constants equal to zero); $\theta_{1}^{(h)}$ is calculated under condition of 'switched on' $\boldsymbol{X}-\boldsymbol{Y}$ hetero-association and 'switched off' complexation of $\boldsymbol{Y}$ with DNA (only the equilibrium constants of interceptors-DNA binding equal to zero); $\theta_{1}$ is the binding density when all equilibrium constants are non-zero.
It is seen from eq. (4.1) that the $A_{D}$ factor is proportional to the fraction of DNA bound ligand $\boldsymbol{X}$, hence, as declared in statement (ii) (see section 4.1), it represents the quantitative measure of biological effect in $(N+1)$-component drug-interceptors-DNA system and is given as a change of biological effect of drug $\boldsymbol{X}$ on addition of interceptors $\boldsymbol{Y}$ relative to the case when interceptors are absent. In this sense the $A_{D}$ factor is similar to standard biological quantities, such as $\mathrm{IC}_{50}$, measured in in vitro experiment and expressed as dimensionless parameters. The examples of re-calculating the experimentally measured in vitro biological effect in terms of $A_{D}$ factor are given in refs. (Evstigneev, 2010; Skamrova et al., 2014; Evstigneev et al., 2008, 2011a; Buchelnikov and Evstigneev, 2014).

The $R_{D}$ factor has the meaning of a ratio of strength of protector to interceptor mechanisms. The range of $R_{D}>1$ corresponds to the predominance of protector action and $R_{D}<1$ corresponds to predominance of the interceptor action.

\subsection{The main equations of the IPA theory}

\subsubsection{The system of mass balance equations}

The most general description of the $(N+1)$-component system of interacting molecules and DNA can be given by means of merging the model of $\mathrm{N}$-component hetero-association (Buchelnikov et al., 2013b) with McGhee - von Hippel equation (3.1) extended to the case of $\mathrm{N}$-competing ligands. The model (Buchelnikov et al., 2013b) is considered to be the most exact among alternative approaches suggested so far and reviewed above, free of any limitation to the length of aggregates or types of hetero-complexes (see ref (Buchelnikov et al., 2019) for review).

For the system of interacting molecules in the presence of polymeric DNA having the total concentration of nucleotide pairs $P_{0}$, the system of mass balance equations takes the form

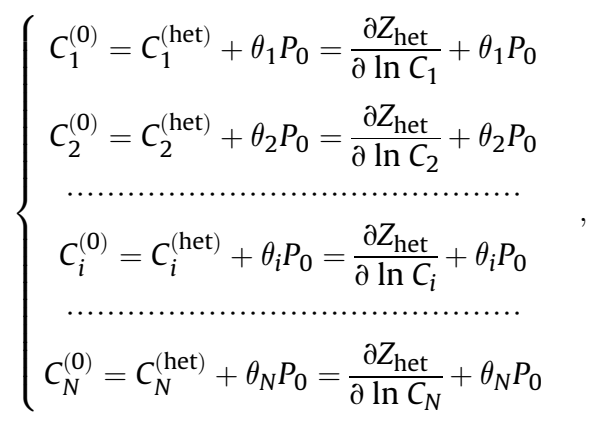

where $C_{i}^{(0)}$ and $C_{i}$ are the total and monomer concentrations of the $i$-type molecules; $C_{i}^{(\text {het })}=\frac{\partial Z_{\text {het }}}{\partial \ln C_{i}}$ is the concentration of the $i$-type molecules existing in all possible homo- and hetero-complexes of any length in $N$-component mixture excluding DNA; $Z_{\text {het }}$ is the grand partition function of the $\mathrm{N}$-component mixture excluding DNA given as (Buchelnikov et al., 2013b)

$$
\begin{aligned}
& Z_{\text {het }}=\frac{1}{2} \gamma\left((\mathbf{I}-\mathbf{G})^{-1}+\left(\mathbf{I}-\mathbf{G}_{\mathbf{d}}\right)^{-1}\right) 1^{\top}, \\
& \gamma=\left(\begin{array}{llllll}
\gamma_{1} & \gamma_{2} & \gamma_{3} & \cdots & \gamma_{N}
\end{array}\right), \quad \gamma_{i}=\frac{C_{i}}{1-K_{i i} C_{i}}, \quad \gamma_{i}^{(2)} \\
& =\frac{C_{i}^{2}}{1-K_{i i}^{2} C_{i}^{2}},
\end{aligned}
$$


$\mathbf{G}=\left(\begin{array}{ccccc}0 & K_{12} \gamma_{2} & K_{13} \gamma_{3} & \cdots & K_{1 N} \gamma_{N} \\ K_{21} \gamma_{1} & 0 & K_{23} \gamma_{3} & \cdots & K_{2 N} \gamma_{N} \\ K_{31} \gamma_{1} & K_{32} \gamma_{2} & 0 & \cdots & K_{3 N} \gamma_{N} \\ \vdots & \vdots & \vdots & \ddots & \vdots \\ K_{N 1} \gamma_{1} & K_{N 2} \gamma_{2} & K_{N 3} \gamma_{3} & \cdots & 0\end{array}\right)$

$\mathbf{G}_{\mathbf{d}}=\left(\begin{array}{ccccc}0 & K_{12}^{2} \gamma_{2}^{(2)} & K_{13}^{2} \gamma_{3}^{(2)} & \cdots & K_{1 N}^{2} \gamma_{N}^{(2)} \\ K_{21}^{2} \gamma_{1}^{(2)} & 0 & K_{23}^{2} \gamma_{3}^{(2)} & \cdots & K_{2 N}^{2} \gamma_{N}^{(2)} \\ K_{31}^{2} \gamma_{1}^{(2)} & K_{32}^{2} \gamma_{2}^{(2)} & 0 & \cdots & K_{3 N}^{2} \gamma_{N}^{(2)} \\ \vdots & \vdots & \vdots & \ddots & \vdots \\ K_{N 1}^{2} \gamma_{1}^{(2)} & K_{N 2}^{2} \gamma_{2}^{(2)} & K_{N 3}^{2} \gamma_{3}^{(2)} & \cdots & 0\end{array}\right)$

I and $\mathbf{1}$ are $N \times N$ and $N \times 1$ unit matrices; $K_{i j}$ and $K_{i i}$ are the equilibrium hetero- and homo-association constants for complexation of the $i$-type with $j$-type molecule;

$\theta_{i}=K_{i P} C_{i}\left(1-\sum_{j=1}^{N} n_{j} \theta_{j}\right)\left(\frac{1-\sum_{j=1}^{N} n_{j} \theta_{j}}{1-\sum_{j=1}^{N}\left(n_{j}-1\right) \theta_{j}}\right)^{n_{i}-1}$

is the standard DNA binding densities for $i$ th ligand with complexation constant $K_{i P}$ and binding site size $n_{i}$. The binding density can be directly related to the mole fraction, $f_{C}^{(i)}$., used in 'oligomer' theories as $f_{C}^{(i)}=\theta_{i} \frac{P_{0}}{C_{i}^{(0)}}$, which establishes direct link between the $R_{D}, A_{D}$ factors in eqs. (3.4) and (4.1).

It is worth noting that the grand partition function, $Z_{\text {het }}$, used in eq. (4.2) and taken from the general hetero-association model (Buchelnikov et al., 2013b), reduces to all major hetero-association models, including those reviewed above and used in early IPA theories. Another important issue to keep in mind is that the equations for $\theta_{i}$ describe the case of non-cooperative and nonspecific drug/interceptor binding with DNA. If the drugs feature some specificity of binding, the expression for $\theta_{i}$ in eq. (4.2) can be replaced with the corresponding expressions known from modifications of standard McGhee - von Hippel theory (e.g. refs (McGhee and von Hippel, 1974; McGhee, 1976)) and well elaborated in nucleic acid and enzyme chemistry.

Solution of eq. (4.2) results in the set of monomer concentrations, $C_{i}$, and drug binding densities, $\theta_{i}$, which enable to compute the concentration of any type of complex present in $(N+1)$ -component system. In particular, it is possible to compute quantities for the drug $\boldsymbol{X}$ under various combinations of 'switched on' and 'switched off equilibrium binding constants, $K_{i j}$ and $K_{i P}$, described in eq. (4.2). It follows that eq. (4.2) provide complete quantitation of the drug-interceptors-DNA system in terms of the IPA theory.

\subsubsection{Test of the appropriateness of the mass balance equations}

The mass balance equation (4.2) use equilibrium homo-/heteroassociation constants, $K_{i j}$, and DNA complexation constants, $K_{i P}$ as the main physico-chemical parameters of molecular complexation. All these parameters were previously derived for all major druginterceptor-DNA pairs in similar solution conditions (see refs (Evstigneev, 2010; Evstigneev et al., 2008; Evstigneev, 2014) and references therein) in separate one- (self-association) or twocomponent (hetero-association and ligand-DNA complexation) systems. The question is whether these parameters are transferrable to more complex $(N+1)$-component system (i.e. are there any specific cooperative effects in multicomponent system which cannot be observed in more simple two-component systems)? This question was subjected to experimental investigation in refs. (Evstigneev et al., 2005, 2006a, 2006c, 2006d, 2007; Buchelnikov et al., 2012, 2013c). Using NMR spectroscopy and spectrophotometry for various drug-interceptor pairs it was shown that the equilibrium constants derived from two-component systems are transferrable to multicomponent solution.

\subsubsection{Parameterization of the mass balance equations}

In order to make the mass balance equation (4.2) applicable for analysis of the competitive binding under in vitro conditions in biological systems, it is necessary to select appropriate concentrations of the components, $C_{i}^{(0)}, P_{0}$, applying the common assumption (v) in such analyses (see section 4.1) that the equilibrium binding constants appearing in eq. (4.2) and measured in independent physico-chemical experiments are the same when dealing with biological systems. The set of such concentrations was previously termed as quasi-physiological and determined separately for the 'oligomer' (4.3a) (Evstigneev, 2010; Evstigneev et al., 2008, 2011a) and 'polymer' (4.3b) (Buchelnikov et al., 2012) models of DNA used in IPA theories:

$$
\begin{aligned}
& C_{1}^{(0)}=10 \mu \mathrm{M}, \quad C_{i}^{(0)}-\text { var }, \quad P_{0}^{\text {oligomer }}=10 \mu \mathrm{M} ; \\
& C_{1}^{(0)}=10 \mu \mathrm{M}, \quad C_{i}^{(0)}-\text { var }, \quad P_{0}=40 \mu \mathrm{M}
\end{aligned}
$$

where 'var' for the concentrations of interceptor molecules, $C_{i}^{(0)}$, means the typical concentration range used to study the synergy of drug-interceptor interaction (e.g. from 0 to units of $\mathrm{mM}$ for methylxanthines (Traganos et al., 1991a; Traganos et al., 1991b; Lyles and Cameron, 2002; Bedner et al., 2001)).

The concentrations (4.3) were previously deduced from in vitro data on the reduction in toxicity of the antitumor antibiotics doxorubicin and novatrone in human leukemia cell lines on addition of caffeine using the 'oligomer' model $(n=4)$ (Evstigneev, 2010; Evstigneev et al., 2008). Recently this result was confirmed in quantification of apoptosis-concentration curve for the anticancer agent topotecan (Evstigneev et al., 2011a) and druginduced granulation of hetero-chromatin in human buccal epithelium cells (Skamrova et al., 2014). In ref (Buchelnikov et al., 2012) it was shown that the 'oligomer' model is a particular case of the general 'polymer' model, and for simple aromatic drugs no significant error in quantitation of the drug-interceptor-DNA system is expected when switching between the 'polymer' and the 'oligomer' models. It follows that applying the scaling factor of $n=$ 4 to the DNA concentration, $P_{0}^{\text {oligomer }}=P_{0} / 4$, the set of quasiphysiological conditions for polymeric DNA may be summarized as $\left(4.3 \mathrm{~b}\right.$ ), where $P_{0}$ is expressed in units of base-pairs (or phosphates) and $P_{0}^{\text {oligomer }}$ is expressed in tetrameric binding sites.

Another important issue necessary to take into consideration is the magnitudes of drug/interceptor-DNA binding constants, which may depend on physico-chemical method (e.g. NMR or spectrophotometry), DNA model (e.g. oligomer or polymer) and binding model (e.g. Scatchard or McGhee - von Hippel) used for their determination. In ref (Buchelnikov et al., 2012) this question was subjected to detailed numerical analysis. The re-derivation of the quasi-physiological conditions (4.3) using the $A_{D}$ factor referenced against the in vitro data in drug-caffeine-DNA systems confirmed the appropriateness of conditions (4.3) with respect to dispersion in magnitudes of microscopic binding constants and binding site sizes in eq. (4.2). However, it was recommended to always use the values of binding parameters determined in similar solution conditions (see refs (Evstigneev et al., 2008; Evstigneev, 2014) for review) using the same DNA model and binding scheme as those employed in eq. (4.2). 
4.3.4. Allowed range of variation of the parameters used in the IPA theory

The parameterization of mass balance equation (4.2) raises a question to what extent an accuracy of estimation of the quasiphysiological conditions (4.3) can influence the predicted magnitude of the $A_{D}$ factor? This question is linked to a more fundamental problem (v) (see section 4.1) of how well the magnitudes of complexation constants and concentrations measured in separate physico-chemical experiments agree with their magnitudes in real cell.

In ref (Evstigneev et al., 2011b) the sensitivity of the $A_{D}$ factor to variation of quasi-physiological conditions was investigated in detail. Assuming the typical error of experimental determination of the binding parameters (binding constants, binding site sizes and concentrations) enabled to conclude that there are three sets of parameters in eq. (4.2) which have the greatest impact on the $A_{D}$ factor, viz. the hetero-association constants, $K_{i j}$, and the ligand-DNA binding constants, $K_{i p}$. The parameters of self-association, $K_{i i}$, and the concentrations, $C_{i}^{(0)}, P_{0}$ exert minor influence. This result is quite expected because $K_{i j}$ are directly linked with the strength of the interceptor mechanism, and $K_{i P}$ are linked with the protector mechanism and the fraction of drug-DNA complexes. Further analysis showed that within the typical error of biological experiment (i.e. setting the allowed dispersion of the $A_{D}$ factor to $15 \%$ ) and depending on the combinations studied, on average $c a .100 \%$ range of deviation of the binding parameters in eq. (4.2) appears to be acceptable. There is a very important outcome because it reveals the fundamental 'inertness' of the $A_{D}$ factor with respect to variation of the physico-chemical parameters of interaction. In previous studies this effect was also noted for particular combinations of the ligands (Evstigneev, 2010; Evstigneev et al., 2006a, 2006b, 2008, 2011a), and can presumably be considered as a general property of the drug-interceptor-DNA systems. This is important because the property of 'inertness', in part, justifies the use of binding parameters in eq. (4.2) (derived from independent physico-chemical experiments; see ref (Kostjukov et al., 2011) for review) for estimation of relative biological effect in the IPA theory, as well as to use rough estimate of the concentrations in quasi-physiological conditions (4.3). It also provides indirect explanation to the reported successes in theoretical description of the dependence of the in vitro biological effect for various DNA binding drugs and interceptor molecules, i.e. refs. (Evstigneev, 2010; Skamrova et al., 2014; Evstigneev et al., 2006a, 2008, 2011a; Buchelnikov and Evstigneev, 2014). However, the general correspondence of the magnitudes of binding parameters to $\mathrm{pH}$, ionic strength and temperature of the biological system under study is the important factor, making the parameterization of eq. (4.2) truly meaningful.

\subsection{General patterns of the $R_{D}, A_{D}$ factors}

Numerical analysis of the dependence of $R_{D}, A_{D}$ factors on concentrations $C_{i}^{(0)}, P_{0}$ (in the 'polymer' theory) and $x_{0}, y_{0}, N_{0}$ (in the 'oligomer' theory) was accomplished in refs. (Evstigneev, 2010; Skamrova et al., 2014; Evstigneev et al., 2005, 2006a, 2006b, 2008, 2011a; Hernandez Santiago et al., 2009; Buchelnikov et al., 2012). The typical $R_{D}, A_{D}$ curves for caffeine (CAF) as classical interceptor molecule are given in Fig. 3. It is seen that for certain combinations the protector action $\left(R_{D}>1\right)$ is dominant over the interceptor action (PI, NOR), and both mechanisms are of comparable efficacy $\left(R_{D} \approx 1\right)$ for the other combinations (PF, DOX, NOV). The very rare case of predominant contribution from the interceptor action $\left(R_{D}<1\right)$ was noted for NOV-flavinmononucleotide-DNA combination (Evstigneev, 2010; Evstigneev et al., 2008) due to strong heteroassociation amplified by intermolecular hydrogen bond between the drug and interceptor (Veselkov et al., 2005). In the range of relatively small interceptor concentrations the concentration dependence of the $R_{D}$ factor is negligible, whereas at high concentrations it levels off to $R_{D} \approx 1$. Analysis performed in refs (Evstigneev, 2010; Evstigneev et al., 2008) based on the 'oligomer' IPA theory showed that in the extreme limit of a great excess of interceptor molecules in solution, i.e. $y_{0} \rightarrow \infty$, evaluation of the $\lim R_{D}=1$ is unity, which means that there is an equal contribution of the 'interceptor/protector' mechanisms. Another extreme limit, $\lim _{y_{0} \rightarrow 0} R_{D}$, yields the relation between equilibrium constants that $y_{0} \rightarrow 0$

$R_{D}=\frac{K_{Y N}}{K_{h}}$,

Eq. (4.4) can be used to estimate the interrelation between the interceptor and protector actions in any $\boldsymbol{X}$-Y-DNA.

The $A_{D}$ factor demonstrates saturation profile indicating the removal of drug molecules from DNA on addition of interceptor. The most important outcome from analysis of the right plot in Fig. 3 is the ability to categorize drugs in descending order for their sensitivity to the addition of interceptor, i.e. PF $>$ NOR $>$ NOV $>$ DOX > PI. It means that the largest synergistic effect on addition of $\mathrm{CAF}$ at $\mathrm{mM}$ concentrations is expected for the mutagen PF and the lowest change for the mutagen PI with DNA. Analysis (Evstigneev, 2010; Evstigneev et al., 2006a, 2008) also showed that the sequence of drugs very weakly depends on $N_{0}$ and $x_{0}$. Moreover,
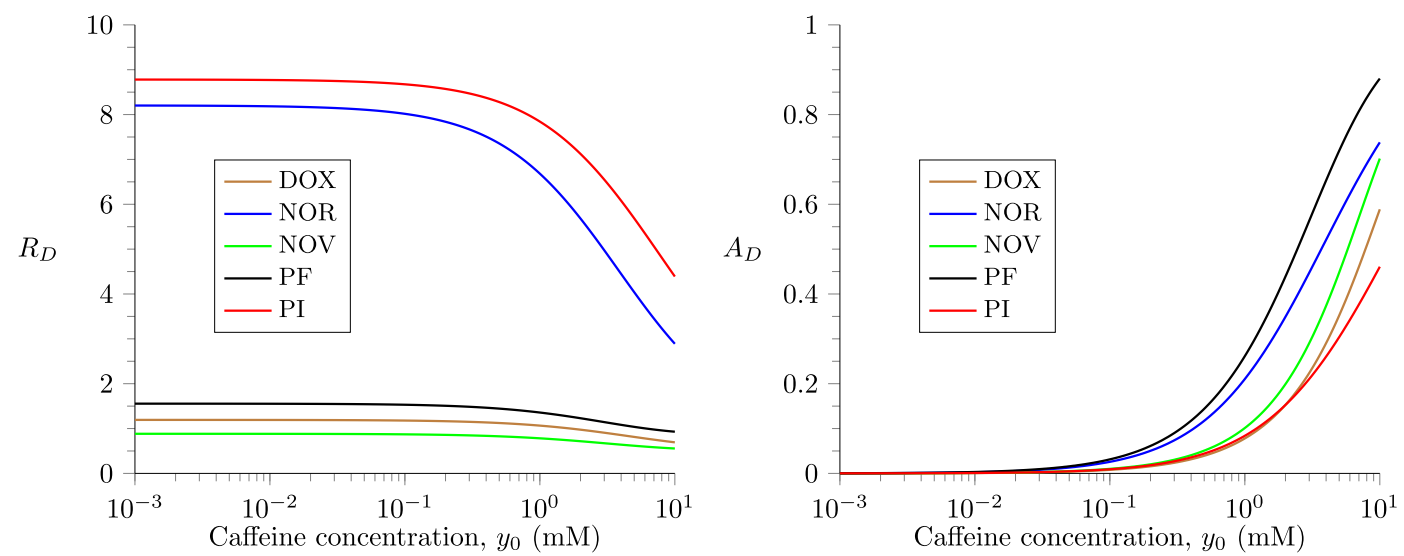

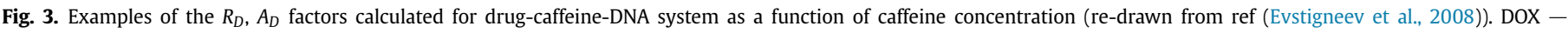
doxorubicin, NOR - norfloxacin, NOV - mitoxantrone, PF - proflavine, PI - propidium iodide. 
that sequence is in good agreement with the sequence of numbers calculated using an empirical relation

$A_{D} \equiv \frac{K_{h}^{2}}{K_{X N}}$

The approximation is good only if the effects of the studied drugs differ from each other by more than ca. $15 \%-20 \%$ in $K_{h}^{2} / K_{X N}$ units. Nevertheless, just using values of the equilibrium heteroassociation constant for $\boldsymbol{X}-\boldsymbol{Y}$ and the $\boldsymbol{X}$-DNA complexation constant, eq. (4.5) can be used to predict within a $20 \%$ accuracy the relative effect of addition of interceptor molecule to one drug relative and to another (all other conditions be equal; the detailed procedure for comparing different drugs in $A_{D}$ terms is given in refs (Evstigneev, 2010; Evstigneev et al., 2008)). In fact, eq. (4.5) also provides a rationale for the direct regulation of biological activity in drug-interceptor systems by varying the equilibrium heteroassociation and complexation constants in different systems.

The $R_{D}, A_{D}$ curves demonstrate relatively weak dependence on the drug and DNA concentrations even at order of magnitude variation of their values (Evstigneev et al., 2005) (i.e. the very approximate quasi-physiological conditions do not affect qualitative conclusions drawn from analysis of $R_{D}, A_{D}$ concentration dependences).

\section{Reduction of the general IPA theory to major partial cases}

\subsection{Reduction of the $(N+1)$-component to three-component drug-interceptor-DNA system}

The three-component drug-interceptor-DNA system is currently the most demanded case of the IPA theory. The reduction of eq. (4.2) down to the three-component case is accomplished by leaving here only two equations for the $\operatorname{drug}(i=1)$ and interceptor $(i=2)$. The next step would be the reduction of the grand partition function, $Z_{\text {het }}$, to the 2-component case of hetero-association. The general approach to perform this operation was given in ref. (Buchelnikov et al., 2013b). The final equations representing (4.2)like mass balance equations were obtained in refs (Buchelnikov et al., 2012; Evstigneev et al., 2011b). for the case of heteroassociation model without any restrictions; in ref (Evstigneev et al., 2011a). for the case of 1:n hetero-association with two types of drugs (antibiotic topotecan in lactone and carboxylate forms) and one type of interceptor. Eq. (3.2) of the reduced 'polymer' theory represent the standard case of 2:n hetero-association model which also directly follows from $Z_{\text {het }}$ (Buchelnikov et al., 2013b).

\subsection{Reduction of the 'polymer' to the 'oligomer' theory}

Once the reduction to the three-component drug-interceptorDNA system is carried out, further transformation of the 'polymer' to 'oligomer' equations of the IPA theory becomes simple (see ref (Buchelnikov et al., 2012) for more details). Assuming that polymeric DNA consists of non-overlapping sites of equal length (four nucleotide pairs) for the drug and the interceptor, it is necessary to put $n_{X}=1, n_{Y}=1$ in eq. (3.1) which yields the standard linear Scatchard equations reducing down to third equation in eq. (3.5) of the 'oligomer' theory.

Evaluation of the first two equations in eq. (3.5) representing the contribution from hetero-association to dynamic equilibrium within the framework of the 'oligomer' theory was accomplished in ref. (Buchelnikov et al., 2013b).

\subsection{The case of the 'oligomer' theory ignoring aggregation}

An accurate determination of the $R_{D}$ and $A_{D}$ factors can be made by solution of the system of mass balance equations. In case of considering self- and/or hetero-association beyond the dimer stage, an accurate analytical solution of that system is unlikely to be possible. However, if self-association of $\boldsymbol{X}$ and $\boldsymbol{Y}$ molecules can be excluded from the analysis and only 1:1 hetero-association considered, then the system of mass balance equations may be simplified down to eq. (5.1). Such assumptions are reasonable because at physiological concentrations $(\mu \mathrm{M})$ the self-association of aromatic drugs as well as high order hetero-association may not be significant.

$$
\left\{\begin{array}{l}
x_{0}=x_{1}+K_{X N} x_{1} N_{1}+K_{h} x_{1} y_{1} \\
y_{0}=y_{1}+K_{Y N} y_{1} N_{1}+K_{h} x_{1} y_{1} \\
N_{0}=N_{1}+K_{X N} x_{1} N_{1}+K_{Y N} y_{1} N_{1}
\end{array}\right.
$$
Under the set of conditions $\left\{N_{0}=x_{0}, \quad x_{0} \ll \frac{1}{K_{h}}, \quad N_{0} \ll \frac{1}{K_{Y N}}\right\}$ solu-
tion of eq. (5.1) gives (Evstigneev et al., 2008)

$$
\left\{\begin{array}{l}
R_{D}=\frac{\sqrt{1+c}+\sqrt{1+4 a+c}}{\sqrt{1+b}+\sqrt{1+4 a+b}} \cdot \frac{\sqrt{1+4 a} \sqrt{1+b}-\sqrt{1+4 a+b}}{\sqrt{1+4 a} \sqrt{1+c}-\sqrt{1+4 a+c}} \\
A_{D}\left(R_{D} \ll 1\right)=\frac{2}{\sqrt{1+4 a}-1} \cdot \frac{\sqrt{1+4 a} \sqrt{1+c}-\sqrt{1+4 a+c}}{\sqrt{1+c}+\sqrt{1+4 a+c}} \\
A_{D}\left(R_{D} \gg 1\right)=\frac{2}{\sqrt{1+4 a}-1} \cdot \frac{\sqrt{1+4 a} \sqrt{1+b}-\sqrt{1+4 a+b}}{\sqrt{1+b}+\sqrt{1+4 a+b}}
\end{array},\right.
$$

where $a=K_{X N} x_{0}, b=K_{Y N} y_{0}, c=K_{h} y_{0}$.

It was shown (Evstigneev et al., 2008) that the solution (5.2) is applicable to certain drug-interceptor pairs.

\subsection{The case of the 'oligomer' theory ignoring interceptor binding with DNA}

One of the most widely spread partial case of the druginterceptor-DNA systems is condition of negligible interceptor binding with DNA, which allows to exclude the protector mechanism from analysis. This case was extensively utilized in analysis of the synergy in drug-chlorophyllin (Dashwood and Guo, 1992; Pietrzak et al., 2006, 2008), drug-methylxanthine (Woziwodzka et al., 2011, 2013b; Buchelnikov and Evstigneev, 2014; Piosik et al., 2002, 2003, 2005, 2010; Ulanowska et al., 2005, 2007; Gołuński et al., 2015, 2016) and drug-fullerene (Skamrova et al., 2014) combinations. Detailed treatment of the interceptor action within the framework of the 'oligomer' IPA theory was accomplished in refs. (Skamrova et al., 2014; Buchelnikov and Evstigneev, 2014). If the aggregation is ignored, $K_{Y N}$ is taken zero and the quasiphysiological conditions (4.3) are applied $\left(N_{0} \approx x_{0}, y_{0} \gg x_{0}\right)$, equation (5.1) result in

$A_{D} \approx K_{h} y_{0}$.

This is the very important result which will be re-visited in section 6 .

\section{Application of the IPA theory to biological data}

\subsection{The point test on proliferating cell lines}

The 'point test', i.e. comparison of $A_{D}$ factors for different druginterceptor systems at single concentration of interceptor, corresponding to reproducible measurement of biological effect, was 
reported in refs. (Evstigneev, 2010; Evstigneev et al., 2008). The authors of refs (Evstigneev, 2010; Evstigneev et al., 2008). used the data of measurements of apoptosis (Traganos et al., 1991a) induced in human leukemia cell line by addition of three antibiotics (mitoxantrone - NOV, doxorubicin - DOX, ellipticine - ELP) alone and together with caffeine (CAF). The effect of addition of CAF to the cell culture together with antibiotic had resulted in lowering of the drugs' cytotoxicity, estimated in $A_{D}$ units as $A_{D}^{\exp }(\mathrm{NOV})=$ $67 \%>A_{D}^{\exp }(\mathrm{DOX})=53 \%>A_{D}^{\exp }(\mathrm{ELP})=27.5 \%$. The computation of $A_{D}$ within the framework of the 'oligomer' IPA theory well matched the experimental sequence for NOV > DOX, which marked the first instance of successful application of the IPA theory to biological data. However, it failed for ELP, and the theoretically predicted sequence had been independent of variation of the binding parameters used in computations. In contrast to NOV/DOX, ELP demonstrates the synergy with CAF only at sequential addition, and shows little interaction with it on simultaneous administration (Traganos et al., 1991a). This falls out of the range of applicability of the IPA theory (see section 4.1) and suggested that the ELP + CAF interaction is governed by mechanisms other than the interceptor/ protector.

\subsection{Evaluation of biological data from concentration dependence of induced biological effect in vitro}

In order to ascertain whether the quantity $A_{D}$ may be used to predict the change in the biological effect of drug on addition of interceptor in vitro, the corresponding experimental apoptosisconcentration curve, $A\left(y_{0}\right)$, measured in human leukemia cell line HL-60 for the action of antibiotic topotecan in combination with caffeine (Traganos et al., 1993), was evaluated in ref. (Evstigneev et al., 2011a). Recalculation of the $A\left(y_{0}\right)$ dataset into $A_{D}$ units within the framework of the 'oligomer' theory had resulted in satisfactory description of the experimental dataset. This result was considered as a significant success of the IPA theory and indirectly confirmed the appropriateness of the quasi-physiological conditions (4.3) and the transferability of the binding parameters measured in independent physico-chemical experiment to biological system in vitro. It was also shown that the accuracy of determination of binding parameters (especially the heteroassociation constant) is an important factor for quantitation of biological effect in drug-interceptor-DNA systems.

The set of successful applications of the IPA theory to different drugs' combinations, described above, had increased a confidence that it was not due to a lucky set of numbers used as input, but reflects the general pattern of aromatic ligands targeting DNA. In ref (Skamrova et al., 2014) it was assumed that if the biological synergy in drug-interceptor pairs is governed mainly by physico-chemical processes of molecular complexation, hence the observed effects should not depend on the type of cellular system used. The studies of the combined effects of aromatic drugs had been reported only for proliferating cell systems, but the general features of its manifestations should be similar in proliferating and non-proliferating cell cultures. Human buccal epithelium cells were selected as a test system to verify this hypothesis, and fullerene $C_{60}$ was taken as an interceptor molecule (Skamrova et al., 2014). A concentrationdependent restoration of the non-disturbed biological state of the living cell exposed to various aromatic compounds was observed on addition of pristine $C_{60}$ fullerenes by means of assessment of heterochromatin structure in the cell nucleus, barrier function of cell membrane and the method of cell microelectrophoresis in buccal epithelium cells. The experimental dependence of the number of heterochromatin granules on the concentration of $C_{60}$ fullerene in the drug- $\mathrm{C}_{60}$ systems tested has been sufficiently well described within the framework of the 'oligomer' IPA theory considering the sole action of the interceptor mechanism. An independent verification of the results was carried out against the drug-caffeine systems, as the classical drug-interceptor systems most well described in literature within the framework of the interceptor/protector action. As a general result, additional strong confirmation of the validity of the IPA theory was obtained. Later on it was shown that $\mathrm{C}_{60}$ fullerene combined with DOX exerts interceptor action on proliferating cell lines in vitro and even in vivo (Panchuk et al., 2015; Prylutska et al., 2014, 2015). In fact, this result had been predicted a priori based on previous knowledge of the pattern of drug-interceptor-DNA systems, which highlights the predictive potential of the IPA theory.

\subsection{Evaluation of biological data from mutagenic test in mutagen- interceptor system}

Chlorophyllin ( $\mathrm{CHL}$ ) has long been recognized as a molecule exerting pronounced antimutagenic potency against various aromatic DNA acting mutagens (Woziwodzka et al., 2013a; Dashwood and Guo, 1992, 1993; Pietrzak et al., 2008). This effect has been interpreted in terms of formation of non-covalent hetero-complexes between the mutagen and CHL resulting in lower accessibility of the mutagen to DNA (Woziwodzka et al., 2013a; Dashwood and Guo, 1992, 1993; Pietrzak et al., 2008) (which is the interceptor mechanism falling within the competency of the IPA theory).

The most representative example of the mutagen-chlorophyllin systems matching the interceptor hypothesis is the antimutagenic action of CHL against imidazo-quinoline type amines (IQ, 2-amino3-methylimidazo[4,5-f]quinoline) in Salmonella typhimurium strain TA98 reviewed by Dashwood (Dashwood and Guo, 1993). Statistical treatment of large IQ-CHL dataset had led to a conclusion about a linear correlation between the antimutagenic potency of chlorophyllin, $\mathrm{IC}_{50}$ (which is the chlorophyllin concentration needed for $50 \%$ suppression of mutagenicity in the cell culture treated with IQ mutagens), and the hetero-association constant of the formation of IQ-CHL complexes, $K_{h}$ :

$\mathrm{IC}_{50} \propto K_{h}$.

Eq. (6.1) currently remains the most classical and undisputed demonstration of the validity of molecular complexation hypothesis when explaining biological synergy in drug-interceptor-DNA systems.

In ref (Buchelnikov and Evstigneev, 2014). it was shown that the $\mathrm{IC}_{50}$ factor may be derived as a partial case of the IPA theory under condition of the sole action of the interceptor mechanism (see section 5.4). If the $\mathrm{IC}_{50}$ factor is given as the concentration of chlorophyllin needed for $50 \%$ suppression of mutagenicity in the mutagen test, hence the following substitutions are valid, viz. $y_{0} \equiv \mathrm{IC}_{50}$ and $A_{D} \equiv 1 / 2$. Further transformation of eq. (5.3) results in the approximate expression for the link between the $\mathrm{IC}_{50}$ and $K_{h}$ factors:

$\mathrm{IC}_{50}=\frac{B}{K_{h}}$,

where $B$ is certain constant.

It is seen that there is a significant difference between eqs. (6.1) and (6.2). Fitting of the Dashwood data (the left plot in Fig. 4 redrawn from ref (Dashwood and Guo, 1993).) with eq. (6.2) gives much better goodness of fit as compared with the linear correlation [see eq. (6.1)] initially reported in the cited paper (Fig. 4). It means that the hyperbolic dependence of biological effect (expressed in the form of the $\mathrm{IC}_{50}$ factor) and the physico-chemical parameter of interaction (expressed in the form of $K_{h}$ ) reflects the fundamental 

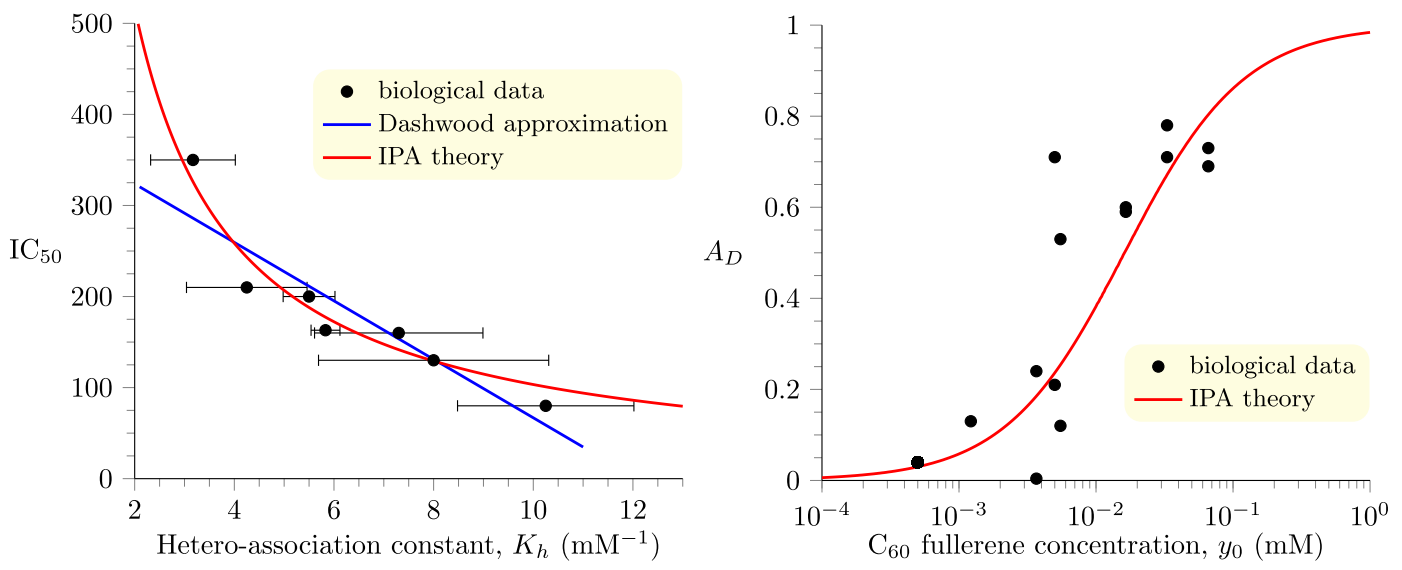

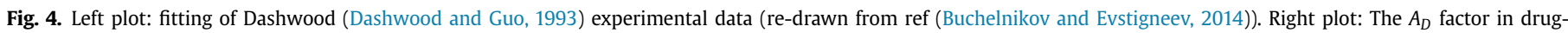
fullerene systems as a function of $\mathrm{C}_{60}$ fullerene concentration (re-drawn from ref (Skamrova et al., 2014)).

action of the interceptor mechanism in its 'pure' form when the other possible mechanisms (such as the protector, or any other) contribute negligibly to experimental observable.

The success in description of the link between the biological and physico-chemical data in mutagen-chlorophyllin systems within the framework of the IPA theory enabled to suggest that similar correlation should be observed for other interceptors as well. With the use of mutagen test in Vibrio harveyi A16 strain the authors of ref (Woziwodzka et al., 2011). reported the dependence of mutagenic activity of the IQ-type amines on the concentration of various xanthines, $y_{0}$, among which the caffeine (CAF) had exerted the most pronounced effect. In ref (Buchelnikov and Evstigneev, 2014). these biological data were recalculated into $A_{D}$ units, and the $A_{D}\left(y_{0}\right)$ dependence was computed under the sole action of the interceptor mechanism. A good fitting of experimental data was reported suggesting that the IQ-CAF systems follow the interceptor mechanism in the same way as the IQ-CHL systems discussed above, and is well described by the IPA theory.

\section{The problem of interrelation of the interceptor/protector actions}

The separate protector and interceptor mechanisms are well characterized in biophysical chemistry and can be quantified by various experimental techniques, whereas there is problem of quantitation for their simultaneous operation in drug-interceptorDNA systems. Traditional view is grounded on experimentally detectable binding of interceptor to drug and interceptor to DNA as a criterion to judge on whether this or that mechanism may be ignored. Currently there is a general agreement between different research groups concerning the role of the interceptor mechanism (Buchelnikov et al., 2012; Gołuński et al., 2013), however, the problem holds with respect to the importance of the protector mechanism. The methylxanthines and chlorophyllin were traditionally treated by UV-Vis spectroscopy which detected negligible binding with DNA and allowed to rule out the protector mechanism in majority of publications (e.g. refs (Hill et al., 2011; Woziwodzka et al., 2011; Woziwodzka et al., 2013b; Kapuscinski et al., 2002; Traganos et al., 1991a; Lyles and Cameron, 2002; Bedner et al., 2001; Dashwood and Guo, 1993; Pietrzak et al., 2008; Pietrzak et al., 2006)). As a consequence, it goes in severe contradiction with the conclusions of the IPA theory, which predicts comparable contribution from the interceptor and protector actions (see section 4.4). The ignoring of the protector mechanism creates difficulties in interpreting the following facts: (i) Direct measurement of the interceptor-DNA binding constant is commonly non-trivial by UV-Vis due to spectral overlap and the relative insensitivity of this technique to small binding constants measured in low concentration range. In contrast the NMR measurements (Hernandez Santiago et al., 2009; Davies et al., 2001), DNA unwinding experiments (Tornaletti et al., 1989) and molecular modeling studies (Deriabina et al., 2006) evidence the CAF-DNA binding. Indirect UV-Vis study of the three-component drugCAF-DNA system (Baranovsky et al., 2009) and direct NMR study of CAF-DNA system (Davies et al., 2001) reported nearly similar complexation constant $K_{Y N} \approx 200 \mathrm{M}^{-1}$. This constant is close to average drug-CAF hetero-association constants, $K_{h}$ (e.g. refs (Evstigneev, 2010; Evstigneev et al., 2008; Piosik et al., 2010; Gołuński et al., 2015; Evstigneev, 2014)), suggesting that the strengths of protector and interceptor bindings could be commensurable. Moreover, the binding of methylxanthines to native DNA is getting more tight ( $K_{Y N}$ increases 10 -fold) in the presence of divalent metal ions (Maria Johnson et al., 2012);

(ii) The CAF-DNA complexation constant, $K_{Y N}$, is $c a .1000$ times lower than the typical drug-DNA complexation constants, $K_{X N}$ (e.g. refs (Evstigneev, 2010; Evstigneev et al., 2008; Piosik et al., 2010; Gołuński et al., 2015)), however, the concentration, $y_{0}$, of caffeine in typical drug-interceptor-DNA systems which causes synergistic effect, falls in mM range (e.g. refs (Traganos et al., 1993; Skamrova et al., 2014; Traganos et al., 1991a; Traganos et al., 1991b)). The latter is $c a$. 1000 times higher than that of the drug, $x_{0}$. It follows that the concentration of the interceptor-DNA complexes may commensurate with the concentration of drug-DNA complexes (which induce biological effect) and the ignoring of protector mechanism may thus be incorrect;

(iii) with an aim to assess the importance of the protector mechanism two independent groups used UV-Vis spectroscopy and generally similar mass balance equations (described in section 5.1), but obtained contradictory conclusions (Buchelnikov et al., 2012; Gołuński et al., 2013);

(iv) the attempt to approach understanding the microscopic picture of simultaneous drug-interceptor binding with DNA was reported in ref. (Maria Johnson et al., 2003a). By means of time correlated single photon counting it was demonstrated that the interceptor binding is not limited to complexation with free drug molecules, but also includes the binding with drug sitting in DNA, which indirectly indicates the importance of the protector mechanism; 
The problem of interrelation of the protector/interceptor actions originates from the difficulty of experimental decomposition of their effects, which remains a challenge for further studies.

\section{The major function of the IPA theory}

Generalizing the above-formulated elements of the IPA theory, its function as a biophysical method of investigation may be summarized as follows:

(i) interpretation of the in vitro biological synergy on simultaneous administration of DNA targeting aromatic drugs and interceptor molecules from single viewpoint, which is the action of two molecular complexation processes in threecomponent drug-interceptor-DNA system, viz. the protector and interceptor actions;

(ii) explanation/prediction of experimental correlation between the binding parameters and biological effect in druginterceptor-DNA systems;

(iii) quantitative estimation of the strengths of interceptor and protector actions (the $R_{D}$ factor);

(iv) quantitative estimation of the relative change of biological effect of drug on addition of interceptor (the $A_{D}$ factor). The possibility to categorize different drugs on their sensitivity to addition of the given interceptor, or different interceptors by their ability to influence biological activity of the given drug;

(v) possibility to predict biological synergy for certain combinations of aromatic drugs based on their ability to form complexes in solution;

(vi) in practical aspect the IPA theory, apart from extension of current scientific knowledge, may also be important in the context of rational drug design for managing drug's response by changing the physico-chemical parameters of molecular complexation.

\section{Conclusion}

The theory of interceptor-protector action (the IPA theory) is probably the only currently known example of self-consistent biophysical theory establishing a quantitative interrelation between parameters measured in independent physico-chemical experiment and in vitro biological experiment for the class of DNA binding drugs. The elements of the theory (basic assumptions, mass balance equations, link to biological experiment etc) provide complete algorithm of analysis, viz. formulation of the mechanism of the observed effects, construction of quantitative model, planning of numerical experiment, theory-to-experiment assessment, which may potentially be applied to any system of DNA targeting aromatic drugs. Such analytical schemes, apart from extension of current scientific knowledge, are important in the context of rational drug design for managing drug's response by changing the physico-chemical parameters of molecular complexation.

\section{Perspectives for further development of the IPA theory}

10.1. Analysis in case of different specificities of drug and interceptor binding with DNA

As noted above the system of mass balance equations, being the central element of the IPA theory, can be simply re-written for the case of taking into account the specificity of ligand-DNA binding (e.g. cooperativity, non-equivalent binding sites etc.). Under such conditions the interrelation of interceptor/protector actions will change.
10.2. Application to other than DNA drug-interceptor-bioreceptor systems

One of the most attractive directions would be the application of the IPA theory to drug-interceptor-enzyme systems. As discussed above, the current level of theory developed with respect to combined action of drugs on proteins is the competitive binding of $\mathrm{N}$ type ligands with protein (Wang et al., 1998), i.e. the interceptor mechanism is ignored. In terms of drug-biopolymer binding the DNA and protein molecules are typically represented as onedimensional lattice. Hence, the mass balance equations construction will be identical for DNA and protein (if the structural factors are not taken into account). Alternatively, the mass balance equations may be replaced with the equations of ligand-protein binding which are well-reviewed in literature and account for various specificities of binding. The main problem to be faced in such analysis should be the parameterization of mass balance equations, $v i z$. the determination of the concentration of binding sites, $N_{0}$, available for drugs' complexation in vitro.

Another attractive issue will be the investigation of druginterceptor-RNA systems. The variability of RNA structure will likely require strict account for interceptor/protector actions even for typical interceptor molecules. For example, the binding of methylxanthines with RNA may be relatively strong (Maria Johnson et al., 2003b).

\subsection{Application to new interceptor molecules}

So far the interceptor/protector binding studies were performed with respect to naturally existing interceptor molecules, such as methylxanthines and polyphenols (see section 2). However, the synthetic molecules, such as fullerenes and carbon nanotubes, seem to also have a potential to be used as interceptor drugs and thereby fall within the competency of the IPA theory.

As already discussed above the biological synergy of aromatic DNA binding drugs administered together with $\mathrm{C}_{60}$ fullerene was recently reported in vitro (Skamrova et al., 2014; Panchuk et al., 2015; Prylutska et al., 2017b; Borowik et al., 2018) and in vivo (Panchuk et al., 2015; Prylutska et al., 2014, 2015). $C_{60}$ fullerene effectively complex DNA binding drugs (Borowik et al., 2018; Bilobrov et al., 2019; Evstigneev et al., 2013; Prylutskyy et al., 2014, 2015a, 2015b) and the in vitro action of fullerene for several studied drugs is well described by the IPA theory (Skamrova et al., 2014). Similar situation seems to be the case for carbon nanotubes (CNT), which bind small molecules (Albertorio et al., 2009; Karachevtsev and Karachevtsev, 2011; Buchelnikov et al., 2014a, 2014b). It has been reported that the non-covalent complexation of aromatic antitumor antibiotics with CNTs may act as a regulator of their biological action (Ali-Boucetta et al., 2008; Liu et al., 2009) in the same way as for DNA binding aromatic drugs. In particular, the adsorption of drug on CNT surface results in lowering of its active concentration in solution thereby limiting its binding with bioreceptor (Ali-Boucetta et al., 2008; Liu et al., 2009).

10.4. Experimental decomposition of the strengths of the interceptor/protector actions

As discussed above this issue remains the most difficult and contradictory point of the IPA theory, and remains as a challenge for further studies.

\subsection{Application to protein-DNA systems}

Important case for application of the IPA theory could be the competitive binding of transcription factors to DNA resulting in 
gene regulation and commonly described by similar statisticalthermodynamical approach to that used above for quantifying drug binding with DNA (e.g. refs (Bintu et al., 2005; Teif, 2007; Segal et al., 2008; Teif and Rippe, 2010)). There is much similarity between the way how the link between physico-chemical parameters of complexation and biological data is established in the IPA theory and the protein-DNA binding models. The latter uses the assumption that the level of gene expression is proportional to the equilibrium probability that protein is bound to the gene of interest (Bintu et al., 2005; Segal et al., 2008), whereas the IPA theory assumes that the change in biological effect of the drug is proportional to the change in its concentration bound with DNA (i.e. the $A_{D}$ factor, see section 4.2). However, unlike the existing protein-DNA binding theories, the IPA theory additionally takes into account the ligand-ligand hetero-association. If that is important in gene regulation, the IPA theory might provide a template for further development of the protein-DNA binding models.

\section{Acknowledgements}

This work was supported by the Council on grants of the President of the Russian Federation for support of leading scientific schools (grant No. NSh-5889.2018.3).

\section{References}

Albertorio, F., Hughes, M.E., Golovchenko, J.A., Branton, D., 2009. Base dependent DNA-carbon nanotube interactions: activation enthalpies and assembly-disassembly control. Nanotechnology 20 (39), 395101.

Ali-Boucetta, H., Al-Jamal, K.T., McCarthy, D., Prato, M., Bianco, A., Kostarelos, K., 2008. Multiwalled carbon nanotube-doxorubicin supramolecular complexes for cancer therapeutics. Chem. Commun. 4, 459-461.

Ardelt, B., Kunicki, J., Traganos, F., Darzynkiewicz, Z., 2001. Chlorophyllin protects cells from the cytostatic and cytotoxic effects of quinacrine mustard but not of nitrogen mustard. Int. J. Oncol. 18 (4), 849-853.

Arimoto, S., Fukuoka, S., Itome, C., Nakano, H., Rai, H., Hayatsu, H., 1993. Binding of polycyclic planar mutagens to chlorophyllin resulting in inhibition of the mutagenic activity. Mutat. Res. Fund Mol. Mech. Mutagen 287 (2), 293-305.

Banerjee, S., Bhowmik, D., Verma, P.K., Mitra, R.K., Sidhhanta, A., Basu, G., Pal, S.K., 2011. Ultrafast spectroscopic study on caffeine mediated dissociation of mutagenic ethidium from synthetic DNA and various cell nuclei. J. Phys. Chem. B 115 (49), 14776-14783.

Baranovskii, S.F., Chernyshev, D.N., Buchel'nikov, A.S., Evstigneev, M.P., 2011. Thermodynamic analysis of complex formation of ethidium bromide with DNA in water solutions. Biophysics 56 (2), 214-219.

Baranovsky, S.F., Bolotin, P.A., Evstigneev, M.P., Chernyshev, D.N., 2009. Interaction of ethidium bromide and caffeine with DNA in aqueous solution. J. Appl. Spectrosc. 76 (1), 132-139.

Bedner, E., Du, L., Traganos, F., Darzynkiewicz, Z., 2001. Caffeine dissociates complexes between DNA and intercalating dyes: application for bleaching fluorochrome-stained cells for their subsequent restaining and analysis by laser scanning cytometry. Cytometry 43 (1), 38-45.

Bernier, J.L., Lohez, M., Helbecque, N., Henichart, J.P., 1989. Effect of combination of $m$-AMSA and doxorubicin on their redox properties and on DNA cleavage. Chem. Biol. Interact. 70 (1-2), 103-115.

Bilobrov, V., Sokolova, V., Prylutska, S., Panchuk, R., Litsis, O., Osetskyi, V., Evstigneev, M., Prylutskyy, Yu, Epple, M., Ritter, U., Rohr, J., 2019. A novel nanoconjugate of Landomycin A with $\mathrm{C}_{60}$ fullerene for cancer targeted therapy: In vitro studies. Cell. Mol. Bioeng. 12 (1), 41-51.

Bintu, L., Buchler, N.E., Garcia, H.G., Gerland, U., Hwa, T., Kondev, J., Phillips, R., 2005 Transcriptional regulation by the numbers: models. Curr. Opin. Genet. Dev. 15 (2), 116-124.

Borowik, A., Prylutskyy, Yu, Kawelski, Ł., Kyzyma, O., Bulavin, L., Ivankov, O., Cherepanov, V., Wyrzykowski, D., Kaźmierkiewicz, R., Gołuński, G. Woziwodzka, A., Evstigneev, M., Ritter, U., Piosik, J., 2018. Does $C_{60}$ fullerene act as a transporter of small aromatic molecules? Colloids Surf., B 164, 134-143.

Buchelnikov, A.S., Evstigneev, M.P. 2014. Quantitative correlation of the in vitro biological effect with parameters of molecular complexation in mutageninterceptor systems. J. Theor. Biol. 357, 268-271.

Buchelnikov, A.S., Hernandez Santiago, A.A., Gonzalez Flores, M., Vazquez Ramirez, R., Davies, D.B., Evstigneev, M.P., 2012. General analysis of competitive binding in drug-interceptor-DNA systems. Eur. Biophys. J. 41 (3), 273-283.

Buchelnikov, A., Evstigneev, V., Rodriguez Oropeza, L., Evstigneev, M., 2013. On the reliability of quantitation of biological effect in drug-interceptor-DNA systems. Eur. Biophys. J. 42 (4), 315-319.

Buchelnikov, A.S., Evstigneev, V.P., Evstigneev, M.P., 2013. General statisticalthermodynamical treatment of one-dimensional multicomponent molecular hetero-assembly in solution. Chem. Phys. 421, 77-83.

Buchelnikov, A.S., Khrustalev, A.F. Evstigneev, M.P., 2013. Development of an analytical approach to study a three-component hetero-association by means of spectrophotometry. Appl. Spectrosc. 67 (1), 29-35.

Buchelnikov, A.S., Voronin, D.P., Kostjukov, V.V., Deryabina, T.A., Khrapatiy, S.V. Prylutskyy, YuI., Ritter, U., Evstigneev, M.P., 2014. Complexation of aromatic drugs with single-walled carbon nanotubes. J. Nano Res. 16 (7), 1-14.

Buchelnikov, A.S., Dovbeshko, G.I., Voronin, D.P., Trachevsky, V.V., Kostjukov, V.V., Evstigneev, M.P., 2014. Spectroscopic study of proflavine adsorption on the carbon nanotube surface. Appl. Spectrosc. 68 (2), 232-237.

Buchelnikov, A.S., Evstigneev, V.P., Evstigneev, M.P., 2019. The hetero-association models of non-covalent molecular complexation. Phys. Chem. Chem. Phys. 21 (15), 7717-7731.

Chin, D.-H., Li, H.-H., Kuo, H.-M., Chao, P.-D.L., Liu, C.-W., 2012. Neocarzinostatin as a probe for DNA protection activity - molecular interaction with caffeine. Mol. Carcinog. 51 (4), 327-338.

Dashwood, R., Guo, D., 1992. Inhibition of 2-amino-3-methylimidazo[4.5-f] (IQ)DNA binding by chlorophyllin: studies of enzyme inhibition and molecular complex formation. Carcinogenesis 13 (7), 1121-1126.

Dashwood, R., Guo, D., 1993. Antimutagenic potency of chlorophyllin in the salmonella assay and its correlation with binding constants of mutagen-inhibitor complexes. Environ. Mol. Mutagen. 22 (3), 164-171.

Davies, D.B., Veselkov, D.A., Kodintsev, V.V., Evstigneev, M.P., Veselkov, A.N., 2000 ${ }^{1} \mathrm{H}$ NMR investigation of the hetero-association of aromatic molecules in aqueous solution: factors involved in the stabilization of complexes of daunomycin and acridine drugs. Mol. Phys. 98 (23), 1961-1971.

Davies, D., Veselkov, D., Djimant, L., Veselkov, A., 2001. Hetero-association of caffeine and aromatic drugs and their competitive binding with a DNA oligomer. Eur. Biophys. J. 30 (5), 354-366.

Davies, D., Veselkov, D., Veselkov, A., 2002. NMR determination of the heteroassociation of phenanthridines with daunomycin and their competitive binding to a DNA oligomer. Eur. Biophys. J. 31 (2), 153-162.

Deriabina, A.S., Grokhlina, T.I., Polteva, N.A., González, E., Poltev, V.I., 2006. Study of mechanisms of some caffeine biological effects via computer simulation of its interactions with DNA fragments. J. Mol. Str., Theochem. 769 (1-3), 97-101.

Evstigneev, M.P., 2010. DNA Binding Aromatic Drug Molecules: Physico-Chemica Interactions and Their Biological Roles. Lambert Academic Publishing, Berlin, $96 \mathrm{pp}$.

Evstigneev, M.P., 2013. Physicochemical mechanisms of synergistic biological action of combinations of aromatic heterocyclic compounds. Org. Chem. Insights 278143.

Evstigneev, M.P., 2014. Hetero-association of aromatic molecules in aqueous solution. Int. Rev. Phys. Chem. 33 (2), 229-273.

Evstigneev, M.P., Shestopalova, A.V., 2014. Structure, Thermodynamics and Energetics of Drug-DNA Interactions: Computer Modeling and Experiment. Application of Computational Techniques in Pharmacy and Medicine. Springer Netherlands, pp. 21-57.

Evstigneev, M.P., Mykhina, YuV., Davies, D.B., 2005. Complexation of daunomycin with a DNA oligomer in the presence of an aromatic vitamin $\left(B_{2}\right)$ determined by NMR spectroscopy. Biophys. Chem. 118 (2-3), 118-127.

Evstigneev, M., Khomich, V., Davies, D., 2006. Complexation of anthracycline drugs with DNA in the presence of caffeine. Eur. Biophys. J. 36 (1), 1-11.

Evstigneev, M.P., Rybakova, K.A., Davies, D.B., 2006. Complexation of norfloxacin with DNA in the presence of caffeine. Biophys. Chem. 121 (2), 84-95.

Evstigneev, M.P. Evstigneev, V.P., Hernandez Santiago, A.A., Davies, D.B., 2006. Effect of a mixture of caffeine and nicotinamide on the solubility of vitamin $\left(B_{2}\right)$ in aqueous solution. Eur. J. Pharm. Sci. 28 (1-2), 59-66.

Evstigneev, M.P., Evstigneev, V.P. Davies, D.B., 2006. NMR investigation of the effect of caffeine on the hetero-association of an anticancer drug with a vitamin Chem. Phys. Lett. 432 (1-3), 248-251.

Evstigneev, M.P., Evstigneev, V.P., Davies, D.B., 2007. A method for analysis of multicomponent systems of interacting aromatic molecules in solution. J. Chem. Phys. 127 (15), 154511.

Evstigneev, M.P., Lantushenko, A.O., Evstigneev, V.P., Mykhina, Y.V., Davies, D.B., 2008. Quantitation of the molecular mechanisms of biological synergism in a mixture of DNA-acting aromatic drugs. Biophys. Chem. 132 (2-3), 148-158.

Evstigneev, M., Mosunov, A., Evstigneev, V., Parkes, H., Davies, D., 2011. Quantification of the interceptor action of caffeine on the in vitro biological effect of the anti-tumour agent topotecan. Eur. Biophys. J. 40 (8), 969-980.

Evstigneev, V.P., Mosunov, A.A., Buchelnikov, A.S., Hernandez Santiago, A.A Evstigneev, M.P., 2011. Complete solution of the problem of one-dimensional non-covalent non-cooperative self-assembly in two-component systems. J. Chem. Phys. 134 (19), 194902.

Evstigneev, M.P., Buchelnikov, A.S., Voronin, D.P., Rubin, YuV., Belous, L.F., Prylutskyy, Yul., Ritter, U., 2013. Complexation of $C_{60}$ fullerene with aromatic drugs. ChemPhysChem 14 (3), 568-578.

Ganapathi, R., Grabowski, D., Schmidt, H., Yen, A., Iliakis, G., 1986. Modulation of adriamycin and $\mathrm{N}$-trifluoroacetyladriamycin-14-valerate induced effects on cell cycle traverse and cytotoxicity in P388 mouse leukemia cells by caffeine and the calmodulin inhibitor trifluoperazine. Cancer Res. 46 (11), 5553-5557.

Gołuński, G., Woziwodzka, A., Iermak, I., Rychłowski, M., Piosik, J., 2013. Modulation of acridine mutagen ICR191 intercalation to DNA by methylxanthines - analysis with mathematical models. Bioorg. Med. Chem. 21 (11), 3280-3289.

Gołuński, G., Borowik, A., Wyrzykowski, D., Woziwodzka, A., Piosik, J., 2015. Pentoxifylline as a modulator of anticancer drug doxorubicin. Part I: reduction of 
doxorubicin DNA binding. Chem. Biol. Interact. 242, 291-298.

Gołuński, G., Borowik, A., Derewońko, N., Kawiak, A., Rychłowski, M., Woziwodzka, A., Piosik, J., 2016. Pentoxifylline as a modulator of anticancer drug doxorubicin. Part II: reduction of doxorubicin DNA binding and alleviation of its biological effects. Biochimie 123, 95-102.

Hernandez Santiago, A., Andrejuk, D., Cervantes Tavera, A., Davies, D. Evstigneev, M., 2009. Complexation of biologically active aromatic compounds with DNA in the presence of theophylline. J. Biol. Phys. 35 (2), 115-126.

Hill, G.M., Moriarity, D.M., Setzer, W.N., 2011. Attenuation of cytotoxic natural product DNA intercalating agents by caffeine. Sci. Pharm. 79 (4), 729-747.

Kakuyamanee Iwazaki, A., Sadzuka, Y., 2001. Effect of methylxanthine derivatives on doxorubicin transport and antitumor activity. Curr. Drug Metabol. 2 (4), 379-395.

Kapuscinski, J., Kimmel, M., 1993. Thermodynamical model of mixed aggregation of intercalators with caffeine in aqueous solution. Biophys. Chem. 46 (2), 153-163.

Kapuscinski, J., Ardelt, B., Piosik, J., Zdunek, M., Darzynkiewicz, Z., 2002. The modulation of the DNA-damaging effect of polycyclic aromatic agents by xanthines: Part I. Reduction of cytostatic effects of quinacrine mustard by caffeine. Biochem. Pharmacol. 63 (4), 625-634.

Karachevtsev, M.V., Karachevtsev, V.A., 2011. Peculiarities of homooligonucleotides wrapping around carbon nanotubes: molecular dynamics modeling. J. Phys. Chem. B 115 (29), 9271-9279.

Kharasch, E.D., Novak, R.F., 1981. The molecular basis for complexation of adriamycin with flavin mononucleotide and flavin adenine dinucleotide. Arch. Biochem. Biophys. 212 (1), 20-36.

Kostjukov, V.V., Khomytova, N.M., Evstigneev, M.P., 2009. Partition of thermodynamic energies of drug-DNA complexation. Biopolymers 91 (9), 773-790.

Kostjukov, V.V., Khomytova, N.M., Hernandez Santiago, A.A., Cervantes Tavera, A.M., Alvarado, J.S., Evstigneev, M.P., 2011. Parsing of the free energy of aromaticaromatic stacking interactions in solution. J. Chem. Thermodyn. 43 (10), 1424-1434.

Larsen, R.W., Jasuja, R., Hetzler, R.K., Muraoka, P.T., Andrada, V.G., Jameson, D.M. 1996. Spectroscopic and molecular modeling studies of caffeine complexes with DNA intercalators. Biophys. J. 70 (1), 443-452.

Liu, Z., Fan, A.C., Rakhra, K., Sherlock, S., Goodwin, A., Chen, X., Yang, Q. Felsher, D.W., Dai, H., 2009. Supramolecular stacking of doxorubicin on carbon nanotubes for in vivo cancer therapy. Angew. Chem. Int. Ed. 48 (41), 7668-7672.

Lyles, M.B., Cameron, I.L., 2002. Caffeine and other xanthines as cytochemical blockers and removers of heterocyclic DNA intercalators from chromatin. Cell Biol. Int. 26 (2), 145-154.

Maria Johnson, I., Bhuvan Kumar, S.G., Malathi, R., 2003. De-intercalation of ethidium bromide and acridine orange by xanthine derivatives and their modulatory effect on anticancer agents: a study of DNA-directed toxicity enlightened by time correlated single photon counting. J. Biomol. Struct. Dyn. 20 (5), 677-686.

Maria Johnson, I., Bhuvan Kumar, S.G., Malathi, R., 2003. RNA binding efficacy of theophylline, theobromine and caffeine. J. Biomol. Struct. Dyn. 20 (5), 687-692.

Maria Johnson, I., Prakash, H., Prathiba, J., Raghunathan, R. Malathi, R., 2012 Spectral analysis of naturally occurring methylxanthines (theophylline, theobromine and caffeine) binding with DNA. PLoS One 7 (12), e50019.

McGhee, J.D., 1976. Theoretical calculations of the helix-coil transition of DNA in the presence of large, cooperatively binding ligands. Biopolymers 15 (7) 1345-1375.

McGhee, J.D., von Hippel, P.H., 1974. Theoretical aspects of DNA-protein interactions: Co-operative and non-co-operative binding of large ligands to a onedimensional homogeneous lattice. J. Mol. Biol. 86 (2), 469-489.

Nechipurenko, YuD., Krylov, A.S., Zasedatelev, A.S., Gursky, G.V., 1984. Cooperative interactions between analogues of distamycin A bound to DNA. Mol. Biol. 18 (2), $332-342$.

Odin, A.P., 1997. Vitamins as antimutagens: advantages and some possible mechanisms of antimutagenic action. Mutat. Res. Rev. Mutat. Res. 386 (1), 39-67.

Panchuk, R.R., Prylutska, S.V., Chumak, V.V., Skorokhyd, N.R., Lehka, L.V., Evstigneev, M.P., Prylutskyy, Yul., Berger, W., Heffeter, P., Scharff, P., Ritter, U., Stoika, R.S., 2015. Application of $C_{60}$ fullerene-doxorubicin complex for tumor cell treatment in vitro and in vivo. J. Biomed. Nanotechnol. 11 (7), 1139-1152.

Peacock, J., Jaynes, J.B., 2017. Using competition assays to quantitatively model cooperative binding by transcription factors and other ligands. Biochim. Biophys. Acta Gen. Subj. 1861 (11A), 2789-2801.

Pietrzak, M., Wieczorek, Z., Wieczorek, J., Darzynkiewicz, Z., 2006. The “interceptor” properties of chlorophyllin measured within the three-component system: intercalator-DNA-chlorophyllin. Biophys. Chem. 123 (1), 11-19.

Pietrzak, M., Halicka, H.D., Wieczorek, Z., Wieczorek, J., Darzynkiewicz, Z., 2008. Attenuation of acridine mutagen ICR-191 - DNA interactions and DNA damage by the mutagen interceptor chlorophyllin. Biophys. Chem. 135 (1-3), 69-75.

Piosik, J., Zdunek, M., Kapuscinski, J., 2002. The modulation by xanthines of the DNA-damaging effect of polycyclic aromatic agents: Part II. The stacking complexes of caffeine with doxorubicin and mitoxantrone. Biochem. Pharmacol. 63 (4), 635-646.

Piosik, J., Ulanowska, K., Gwizdek-Wiśniewska, A., Czyż, A., Kapuscinski, J. Wegrzyn, G., 2003. Alleviation of mutagenic effects of polycyclic aromatic agents (quinacrine mustard, ICR-191 and ICR-170) by caffeine and pentoxifylline. Mutat. Res. Fund Mol. Mech. Mutagen 530 (1-2), 47-57.

Piosik, J., Gwizdek-Wiśniewska, A., Ulanowska, K., Ochociński, J., Czyż, A., Węgrzyn, G., 2005. Methylxanthines (caffeine, pentoxifylline and theophylline) decrease the mutagenic effect of daunomycin, doxorubicin and mitoxantrone.
Acta Biochim. Pol. 52 (4), 923-926.

Piosik, J., Wasielewski, K., Woziwodzka, A., Śledź, W., Gwizdek-Wisniewska, A., 2010. De-intercalation of ethidium bromide and propidium iodine from DNA in the presence of caffeine. Cent. Eur. J. Biol. 5 (1), 59-66.

Prylutska, S., Grynyuk, I., Matyshevska, O., Prylutskyy, Yu, Evstigneev, M., Scharff, P. Ritter, U., 2014. $C_{60}$ fullerene as synergistic agent in tumor-inhibitory doxorubicin treatment. Drugs R 14 (4), 333-340.

Prylutska, S., Skivka, L., Didenko, G., Prylutskyy, Y., Evstigneev, M., Potebnya, G., Panchuk, R., Stoika, R., Ritter, U., Scharff, P., 2015. Complex of $C_{60}$ fullerene with doxorubicin as a promising agent in antitumor therapy. Nanoscale Res. Lett. 10 (1), 499-505.

Prylutska, S., Politenkova, S., Afanasieva, K., Korolovych, V., Bogutska, K., Sivolob, A., Skivka, L., Evstigneev, M. Kostjukov, V., Prylutskyy, Yu, Ritter, U. 2017. A nanocomplex of $\mathrm{C}_{60}$ fullerene with cisplatin: design, characterization and toxicity. Beilstein J. Nanotechnol. 8, 1494-1501.

Prylutska, S., Panchuk, R., Gołuński, G., Skivka, L., Prylutskyy, Yu, Hurmach, V., Skorohyd, N., Borowik, A., Woziwodzka, A., Piosik, J., Kyzyma, O., Garamus, V., Bulavin, L., Evstigneev, M., Buchelnikov, A., Stoika, R., Berger, W., Ritter, U., Scharff, P., 2017. $C_{60}$ fullerene enhances cisplatin anticancer activity and overcomes tumor cell drug resistance. Nano Res 10 (2), 652-671.

Prylutskyy, YuI., Evstigneev, M.P., Pashkova, I.S., Wyrzykowski, D., Woziwodzka, A., Gołuński, G., Piosik, J., Cherepanov, V.V., Ritter, U., 2014. Characterization of $C_{60}$ fullerene complexation with antibiotic doxorubicin. Phys. Chem. Chem. Phys. 16 (42), 23164-23172.

Prylutskyy, YuI., Evstigneev, M.P., Cherepanov, V.V., Kyzyma, O.A., Bulavin, L.A., Davidenko, N.A., Scharff, P., 2015. Structural organization of $\mathrm{C}_{60}$ fullerene, doxorubicin, and their complex in physiological solution as promising antitumor agents. J. Nano Res. 17, 45.

Prylutskyy, YuI., Cherepanov, V.V., Evstigneev, M.P., Kyzyma, O.A., Petrenko, V.I., Styopkin, V.I., Bulavin, L.A., Davidenko, N.A., Wyrzykowski, D., Woziwodzka, A., Piosik, J., Kaźmierkiewicz, R., Ritter, U., 2015. Structural self-organization of $C_{60}$ and cisplatin in physiological solution. Phys. Chem. Chem. Phys. 17 (39), 26084-26092.

Raiczyk, G.B., Pinto, J., 1988. Inhibition of flavin metabolism by adriamycin in skeletal muscle. Biochem. Pharmacol. 37 (9), 1741-1744.

Ramu, A., Mehta, M.M., Liu, J., Turyan, I., Aleksic, A., 2000. The riboflavin-mediated photooxidation of doxorubicin. Cancer Chemother. Pharmacol. 46 (6), 449-458.

Ridge, G.S., Bailly, C., Graves, D.E., Waring, M.J., 1994. Daunomycin modifies the sequence-selective recognition of DNA by actinomycin. Nucleic Acids Res. 22 (24), 5241-5246.

Sadzuka, Y., Mochizuki, E., Takino, Y., 1995. Mechanism of caffeine modulation of the antitumor activity of adriamycin. Toxicol. Lett. 75 (1-3), 39-49.

Schwab, C.E., Huber, W.W., Parzefall, W., Hietsch, G., Kassie, F., Schulte-Hermann, R., Knasmüller, S., 2000. Search for compounds that inhibit the genotoxic and carcinogenic effects of heterocyclic aromatic amines. Crit. Rev. Toxicol. 30 (1), $1-69$.

Segal, E., Raveh-Sadka, T., Schroeder, M., Unnerstall, U., Gaul, U., 2008. Predicting expression patterns from regulatory sequence in Drosophila segmentation. Nature 451, 535-540.

Skamrova, G.B., Laponogov, I., Buchelnikov, A.S., Shckorbatov, Y.G., Prylutska, S.V., Ritter, U., Prylutskyy, YuI., Evstigneev, M.P., 2014. Interceptor effect of $C_{60}$ fullerene on the in vitro action of aromatic drug molecules. Eur. Biophys. J. 43 $(6-7), 265-276$

Sorensen, M., Sehested, M., Jensen, P.B., 1997. pH-Dependent regulation of camptothecin-induced cytotoxicity and cleavable complex formation by the antimalarial agent chloroquine. Biochem. Pharmacol. 54 (3), 373-380.

Tachino, N., Guo, D., Dashwood, W.M., Yamane, S., Larsen, R., Dashwood, R., 1994. Mechanisms of the in vitro antimutagenic action of chlorophyllin against benzo [a]pyrene: studies of enzyme inhibition, molecular complex formation and degradation of the ultimate carcinogen. Mutat. Res. Fund Mol. Mech. Mutagen 308 (2), 191-203.

Teif, V.B., 2007. General transfer matrix formalism to calculate DNA-protein-drug binding in gene regulation: application to $\mathrm{O}_{\mathrm{R}}$ operator of phage $\lambda$. Nucleic Acids Res. 35 (11). Art. No. e80.

Teif, V.B., Rippe, K., 2010. Statistical-mechanical lattice models for protein-DNA binding in chromatin. J. Phys. Condens. Matter 22. Art. No. 414105.

Tornaletti, S., Russo, P., Parodi, S., Pedrini, A.M., 1989. Studies on DNA binding of caffeine and derivatives: evidence of intercalation by DNA-unwinding experiments. Biochim. Biophys. Acta 1007 (1), 112-115.

Traganos, F., Kapuscinski, J., Darzynkiewicz, Z., 1991. Caffeine modulates the effects of DNA-intercalating drugs in vitro: a flow cytometric and spectrophotometric analysis of caffeine interaction with novantrone, doxorubicin, ellipticine, and the doxorubicin analogue Ap198. Cancer Res. 51 (14), 3682-3689.

Traganos, F., Kaminska-Eddy, B., Darzynkiewicz, Z., 1991. Caffeine reverses the cytotoxic and cell kinetic effects of Novantrone (mitoxantrone). Cell Prolif 24 (3), 305-319.

Traganos, F., Kapuscinski, J., Gong, J., Ardelt, B., Darzynkiewicz, R.J., Darzynkiewicz, Z., 1993. Caffeine Prevents apoptosis and cell cycle effects induced by camptothecin or topotecan in HL-60 cells. Cancer Res. 53 (19), 4613-4618.

Ulanowska, K., Piosik, J., Gwizdek-Wiśniewska, A., Wȩgrzyn, G., 2005. Formation of stacking complexes between caffeine (1,2,3-trimethylxanthine) and 1-methyl4-phenyl-1,2,3,6-tetrahydropyridine may attenuate biological effects of this neurotoxin. Bioorg. Chem. 33 (5), 402-413.

Ulanowska, K., Piosik, J., Gwizdek-Wiśniewska, A., Wȩgrzyn, G., 2007. Impaired 
mutagenic activities of MPDP+ (1-methyl-4-phenyl-2,3-dihydropyridinium) and MPP+ (1-methyl-4-phenylpyridinium) due to their interactions with methylxanthines. Bioorg. Med. Chem. 15 (15), 5150-5157.

Veselkov, D.A., Davies, D.B., Djimant, L.N., Veselkov, A.N., 2000. Molecular basis of the protective action of caffeine on the complexation of intercalating ligands with DNA. Biopolym. Cell 16 (6), 468-481.

Veselkov, A.N., Vysotsky, S.A., Evstigneev, M.P., Veselkov, D.A., Djimant, L.N., Bolotin, P.A., Davies, D.B., 2002. ${ }^{1} \mathrm{H}-\mathrm{NMR}$ analysis of the interaction of antibiotic mitoxantrone with DNA in the presence of caffeine in aqueous solution. Biopolym. Cell 18 (4), 287-296.

Veselkov, A.N., Evstigneev, M.P., Rozvadovska, A.O., Mukhina, Y.V., Davies, D.B., 2005. A Structural and thermodynamic analysis of novatrone and flavin mononucleotide heteroassociation in aqueous solution by ${ }^{1} \mathrm{H}$ NMR spectroscopy. Russ. J. Bioorg. Chem. 31 (5), 453-459.

Wang, H., Zou, H., Zhang, Y., 1998. Quantitative study of competitive binding of drugs to protein by microdialysis/high-performance liquid chromatography Anal. Chem. 70 (2), 373-377.

Woziwodzka, A., Gwizdek-Wiśniewska, A., Piosik, J., 2011. Caffeine, pentoxifylline and theophylline form stacking complexes with IQ-type heterocyclic aromatic amines. Bioorg. Chem. 39 (1), 10-17.

Woziwodzka, A., Gołuński, G., Piosik, J., 2013. Heterocyclic aromatic amines heterocomplexation with biologically active aromatic compounds and its possible role in chemoprevention. ISRN Biophysics 740821.

Woziwodzka, A., Gołuński, G., Wyrzykowski, D., Kaźmierkiewicz, R., Piosik, J., 2013. Caffeine and other methylxanthines as interceptors of food-borne aromatic mutagens: inhibition of Trp-P-1 and Trp-P-2 mutagenic activity. Chem. Res. Toxicol. 26 (11), 1660-1673.

Zasedatelev, A.S., Gursky, G.V., Volkenstein, M.V., 1971. Theory of one-dimensiona adsorption. I. Binding of small molecules to linear homopolymer. Mol. Biol. 5 (2), 245-251. 